\title{
How Does the dGEMRIC Index Change After Surgical Treatment for FAI? A Prospective Controlled Study: Preliminary Results
}

\author{
Florian Schmaranzer MD, Pascal C. Haefeli MD, Markus S. Hanke MD, \\ Emanuel F. Liechti MD, MSc, Stefan F. Werlen MD, Klaus A. Siebenrock MD, \\ Moritz Tannast MD
}

Published online: 5 October 2016

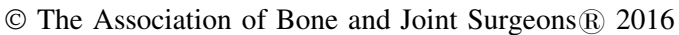

\begin{abstract}
Background Delayed gadolinium-enhanced MRI of cartilage (dGEMRIC) allows an objective, noninvasive, and longitudinal quantification of biochemical cartilage properties. Although dGEMRIC has been used to monitor the course of cartilage degeneration after periacetabular osteotomy (PAO) for correction of hip dysplasia, such longitudinal data are currently lacking for femoroacetabular impingement (FAI).

Questions/purposes (1) How does the mean acetabular and femoral dGEMRIC index change after surgery for FAI at 1-year followup compared with a similar group of patients with FAI treated without surgery? (2) Does the
\end{abstract}

Two of the authors (KAS, MT) have received funding from the Swiss National Science Foundation.

All ICMJE Conflict of Interest Forms for authors and Clinical

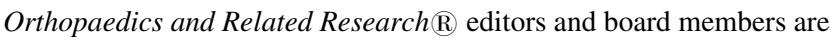
on file with the publication and can be viewed on request.

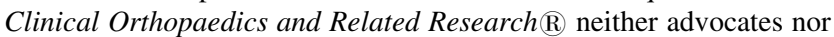
endorses the use of any treatment, drug, or device. Readers are encouraged to always seek additional information, including FDAapproval status, of any drug or device prior to clinical use.

Each author certifies that his or her institution approved the human protocol for this investigation, that all investigations were conducted in conformity with ethical principles of research, and that informed consent for participation in the study was obtained.

This work has been mainly performed at the Department of Orthopaedic Surgery, Inselspital, University of Bern, Bern, Switzerland.

F. Schmaranzer ( $)$, P. C. Haefeli, M. S. Hanke, E. F. Liechti, K. A. Siebenrock, M. Tannast

Department of Orthopaedic Surgery, Inselspital, University of

Bern, Freiburgstrasse, Bern 3010, Switzerland

e-mail: florian.schmaranzer@insel.ch

S. F. Werlen

Department of Radiology, Sonnenhof Clinic, Bern, Switzerland regional distribution of the acetabular and femoral dGEMRIC index change for the two groups over time? (3) Is there a correlation between the baseline dGEMRIC index and the change of patient-reported outcome measures (PROMs) at 1-year followup? (4) Among those treated surgically, can dGEMRIC indices distinguish between intact and degenerated cartilage?

Methods We performed a prospective, comparative, nonrandomized, longitudinal study. At the time of enrollment, the patients' decision whether to undergo surgery or choose nonoperative treatment was not made yet. Thirtynine patients (40 hips) who underwent either joint-preserving surgery for FAI (20 hips) or nonoperative treatment (20 hips) were included. The two groups did not differ regarding Tönnis osteoarthritis score, preoperative PROMs, or baseline dGEMRIC indices. There were more women $(60 \%$ versus $30 \%, \mathrm{p}=0.003)$ in the nonoperative group and patients were older $(36 \pm 8$ years versus $30 \pm 8$ years, $\mathrm{p}=0.026$ ) and had lower alpha angles $\left(65^{\circ} \pm 10^{\circ}\right.$ versus $\left.73^{\circ} \pm 12^{\circ}, \mathrm{p}=0.022\right)$ compared with the operative group. We used a 3.0-T scanner and a threedimensional dual flip-angle gradient-echo technique for the dGEMRIC technique for the baseline and the 1-year followup measurements. dGEMRIC indices of femoral and acetabular cartilage were measured separately on the initial and followup radial dGEMRIC reformats in direct comparison with morphologic radial images. Regions of interest were placed manually peripherally and centrally within the cartilage based on anatomic landmarks at the clockface positions. The WOMAC, the Hip disability and Osteoarthritis Outcome Score, and the modified Harris hip score were used as PROMs. Among those treated surgically, the intraoperative damage according to the Beck grading was recorded and compared with the baseline dGEMRIC indices. 
Results Although both the operative and the nonoperative groups experienced decreased dGEMRIC indices, the declines were more pronounced in the operative group $(-96 \pm 112 \mathrm{~ms}$ versus $-16 \pm 101 \mathrm{~ms}$ on the acetabular side and $-96 \pm 123 \mathrm{~ms}$ versus $-21 \pm 83 \mathrm{~ms}$ on the femoral side in the operative and nonoperative groups, respectively; $\mathrm{p}<0.001$ for both). Patients undergoing hip arthroscopy and surgical hip dislocation experienced decreased dGEMRIC indices; the decline in femoral dGEMRIC indices was more pronounced in hips after surgical hip dislocation $(-120 \pm 137 \mathrm{~ms}$ versus $-61 \pm 89 \mathrm{~ms}, \mathrm{p}=0.002)$. In the operative group a decline in dGEMRIC indices was observed in 43 of 44 regions over time. In the nonoperative group a decline in dGEMRIC indices was observed in four of 44 regions over time. The strongest correlation among patients treated surgically was found between the change in WOMAC and baseline dGEMRIC indices for the entire joint $(\mathrm{R}=0.788$, $\mathrm{p}<0.001)$. Among those treated nonoperatively, no correlation between baseline dGEMRIC indices and change in PROMs was found. In the posterosuperior quadrant, the dGEMRIC index was higher for patients with intact cartilage compared with hips with chondral lesions $(592 \pm 203 \mathrm{~ms}$ versus $444 \pm 205 \mathrm{~ms}, \mathrm{p}<0.001)$.

Conclusions We found a decline in acetabular, femoral, and regional dGEMRIC indices for the surgically treated group at 1-year followup despite an improvement in all PROMs. We observed a similar but less pronounced decrease in the dGEMRIC index in symptomatic patients without surgical treatment indicating continuous cartilage degeneration. Although treatment of FAI is intended to alter the forces acting across the hip by eliminating impingement, its effects on cartilage biology are not clear. dGEMRIC provides a noninvasive method of assessing these effects. Longer term studies will be needed to determine whether the matrix changes of the bradytrophic cartilage seen here are permanent or clinically important. Level of Evidence Level II, therapeutic study.

\section{Introduction}

The concept of femoroacetabular impingement (FAI) is based on a motion-driven conflict of the femur and the acetabulum, which predisposes to premature osteoarthritis of the hip [11, 12]. The establishment of this concept has led to a tremendous increase in numbers of joint-preserving procedures of the hip [24]. Surgical decision-making for FAI should be comprehensive and should include multimodal imaging assessment of the bony morphology and the associated chondrolabral lesions. Although FAI correction by surgical hip dislocation can provide good clinical outcomes at 10 years in appropriately selected patients, the effects of both hip preservation surgery and FAI on cartilage integrity are unclear [43].

Plain radiographs enable only indirect visualization of cartilage and standard, conventional MRI techniques are restricted to the detection of macroscopic chondral damage [7, 36, 46]. The vast majority of patients eligible for jointpreserving hip surgery present without classic signs of osteoarthritis on conventional radiographs. However, many already have severe cartilage lesions at the time of surgery, which are associated with a higher risk of persistent pain, progressive arthritis and subsequent conversion to THA [35]. Hence, accurate preoperative identification and quantification of cartilage degeneration with more sensitive tools should enable selection of those patients who benefit most from surgery.

Several advanced MRI-based techniques (T2, T2*, T1 rho) can be used to quantitatively map cartilage in a noninvasive fashion. Among these, delayed gadoliniumenhanced MRI of cartilage (dGEMRIC) has been used most frequently in the hip [8-10, 16-18, 21, 22, 25, 26, 41]. dGEMRIC involves injection of an MRI hydrophilic contrast agent, $\operatorname{Gd}(\mathrm{DTPA})^{2-}[21,22]$, with subsequent imaging 90 minutes later to enable the contrast agent to penetrate the cartilage tissue. Because the contrast agent is negatively charged, it will have difficulty penetrating normal cartilage with abundant glycosaminoglycan (GAG), because the negatively charged GAG will repel it. In contrast, the agent will more easily penetrate degraded cartilage with less GAG, because the negative charge is less. Thus, a higher dGEMRIC index indicates healthier cartilage (Fig. 1) [59]. Similar to the knee [4, 34], dGEMRIC is a promising tool to quantify cartilage healing or degeneration before and after joint-preserving hip surgery and to monitor the natural course of hip diseases. Recently, the short-term effects of periacetabular osteotomy (PAO) for treatment of hip dysplasia on biochemical cartilage properties have been investigated [16, 17]. In these first reports a drop in dGEMRIC indices after 1 year and partial recovery after 2 years were observed [16, 17]. Although the prognostic value of dGEMRIC to predict early failure after PAO has been demonstrated [10, 25], the role of preoperative cartilage assessment with dGEMRIC in predicting clinical outcome after FAI surgery is yet to be defined [9, 18]. Theoretically FAI surgery could lead to "recovery" of cartilage properties as assessed with dGMERIC by eliminating the bony conflict; conversely, surgery could cause worsening of cartilage degeneration by alterations in biomechanics.

Thus, we performed a planned interim analysis and asked: (1) How does the mean acetabular and femoral dGEMRIC index change after surgery for FAI at 1-year followup compared with a similar group of patients with FAI treated without surgery who thus represented the 


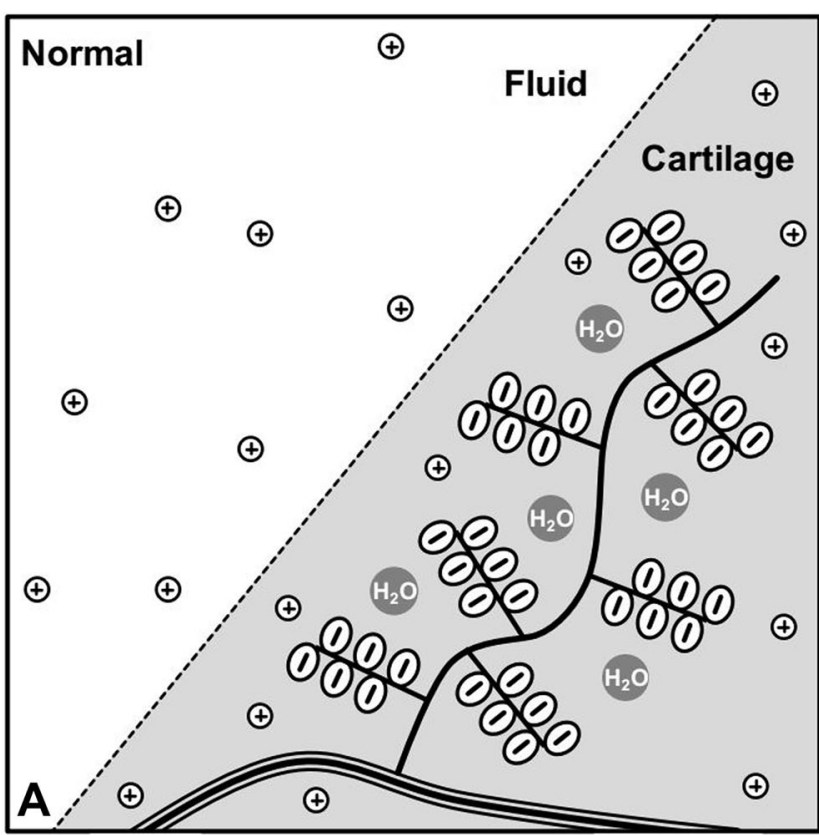

Fig. 1A-B (A) A schematic drawing of intact biochemical cartilage composition is shown. (B) A degenerated cartilage is characterized by a loss of GAG and collagen and an increase of water. The negatively

natural course of the disease? (2) Does the regional distribution of the acetabular and femoral dGEMRIC index change for the two groups over time? (3) Is there a correlation between the baseline dGEMRIC index and the change of patient-reported outcome measures (PROMs) (Western Ontario and McMaster Universities Osteoarthritis Index [WOMAC], Hip disability and Osteoarthritis Outcome Score [HOOS], modified Harris hip score [mHHS]) at 1-year followup? (4) Among those treated surgically, are dGEMRIC indices able to distinguish between intact and degenerated cartilage?

\section{Patients and Methods}

We performed a prospective, comparative, nonrandomized, longitudinal study comparing the dGEMRIC index of patients undergoing surgery for symptomatic FAI compared with FAI patients who had been treated nonoperatively as a control group (natural history). This 1year followup study is a first prespecified interim analysis. Further 3-year and 5-year followup is planned in this patient cohort. Patients were enrolled after institutional review board approval (Fig. 2). Between September 2012 and April 2016, indirect MR arthrography with intravenous administration of contrast agent and acquisition of threedimensional T1 maps for measurement of dGEMRIC indices were performed in 105 patients (116 hips) with

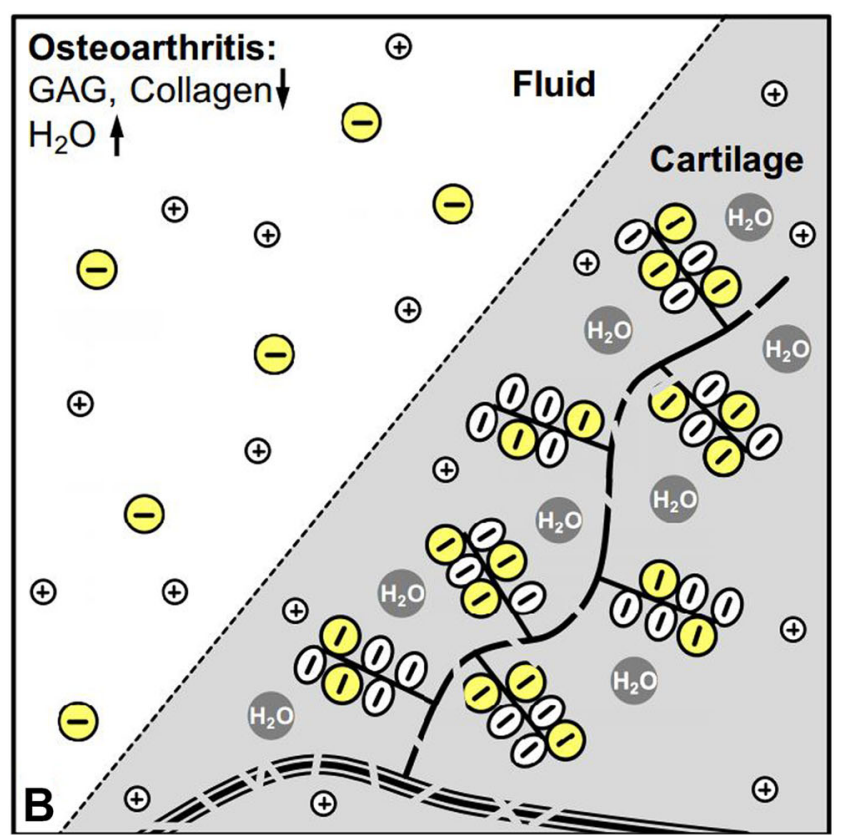

charged gadolinium molecules replace the lost GAGs, which can be measured with MRI.

suspected FAI. We excluded three patients (three hips) with previous surgery, two patients (three hips) with childhood diseases such as Legg-Calvé-Perthes disease or slipped capital femoral epiphysis, four patients (four hips) with no confirmed FAI, and one patient (one hip) with endstage osteoarthritis (Grade 3 according to Tönnis [54]), leaving 95 patients (105 hips) with symptomatic FAI. At the time of enrollment, patient decision to undergo surgery or to choose nonoperative treatment was not made yet. We offered joint-preserving surgery to all these patients. The final decision to undergo surgery was made by the patient leaving 45 patients (47 hips) treated operatively and 56 patients (58 hips) treated nonoperatively (six patients had an operatively and nonoperatively treated side, two patients underwent bilateral operative/nonoperative treatment). Of those, 48 patients (55 hips) were not yet available for a minimum followup of 1 year at the time of data evaluation (three patients had an operatively and nonoperatively treated side, two patients underwent bilateral nonoperative treatment, two patients had $\geq 1$-year followup only for one side). Ten patients (10 hips) refused to come back for a followup MRI. This left 19 patients (20 hips) in the operative group and 20 patients (20 hips) in the nonoperative group with a complete data set and followup (two patients had an operatively and nonoperatively treated side, one patient underwent bilateral surgery).

Based on the primary research question (change of baseline dGEMRIC value versus 1-year followup), we 


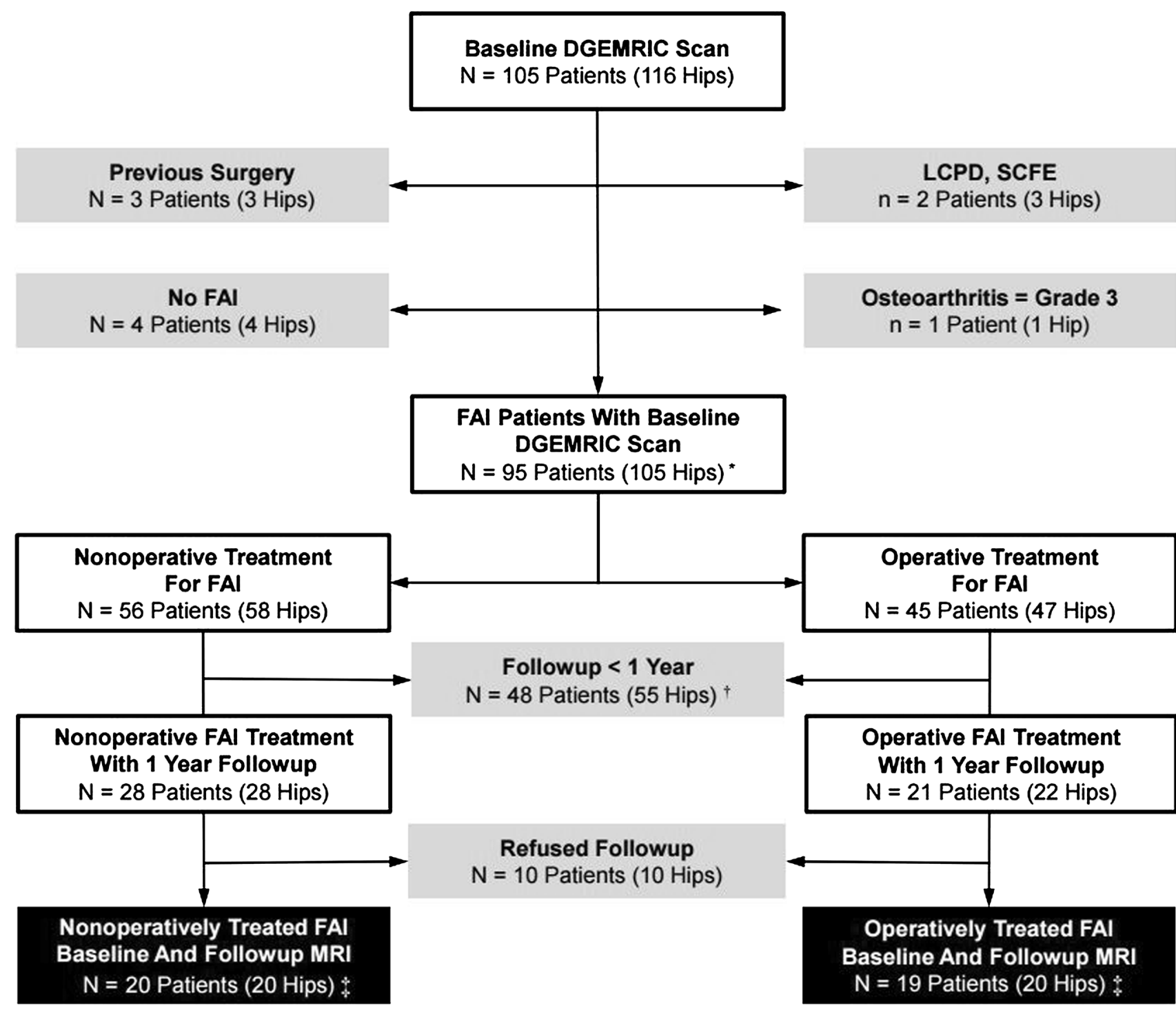

Fig. 2 This flowchart shows the recruitment of the patients involved in our prospective study. ${ }^{*}$ Six patients had an operatively and nonoperatively treated side; two patients underwent bilateral operative/nonoperative treatment; ${ }^{\dagger}$ three patients had an operatively and nonoperatively treated side, two patients underwent bilateral

nonoperative treatment, and two patients had $\geq 1$-year followup only for one side. \$Two patients had an operatively and nonoperatively treated side; one patient underwent bilateral surgery. LCPD $=$ LeggCalvé-Perthes disease; SCFE = slipped capital femoral epiphysis.

performed a power analysis using $\mathrm{G}^{*}$ Power (Version 3.1.9.2; University of Dusseldorf, Düsseldorf, Germany). Given a mean preoperative acetabular T1 value in symptomatic FAI hips of $447 \mathrm{~ms}$ [58], an expected difference of the T1 value $71 \mathrm{~ms}$ [17], and an estimated SD of $120 \mathrm{~ms}$ [17], we calculated a minimal sample size of 20 individuals for each group to provide a level of $\alpha$ of 0.05 and a level of $\beta$ of 0.20 . More patients were enrolled in the study group to perform further subgroup analyses in the future, which are beyond the scope of this preliminary study.

The two groups were comparable regarding side, height, weight, body mass index, and Tönnis osteoarthritis grade
[54] (Table 1). Furthermore, they were comparable for lateral center-edge angle, extrusion index, acetabular index, prevalence of positive crossover/posterior wall/ischial spine/protrusio signs, retroversion index, femoral torsion, and neck shaft angle (Table 2). In particular, they were comparable regarding their preoperative PROMs (WOMAC, HOOS, mHHS; [Table 3]) and their baseline dGEMRIC value (overall and for all regions of interest [ROIs] defined later; [Table 4]). However, there were more women in the nonoperative group than in the operative group $(60 \%$ female versus $30 \%, \mathrm{p}=0.003)$ and subjects were older in the conservatively treated group (mean 
Table 1. Demographic characteristics of study groups

\begin{tabular}{|c|c|c|c|}
\hline Parameter & Nonoperative group & Operative group & $\mathrm{p}$ value \\
\hline Number of patients (hips) & $20(20)$ & $19(20)$ & - \\
\hline Age (years) & $36 \pm 8(21-47)$ & $30 \pm 8(19-47)$ & 0.026 \\
\hline Number of hips with Tönnis osteoarthritis Grade $>0(\%)$ & $9(45)$ & $9(45)$ & 1 \\
\hline Side (\% [hips] left of all hips per group) & $9(45)$ & $10(50)$ & 0.653 \\
\hline Sex (\% [hips] women of all hips per group) & $12(60)$ & $6(30)$ & 0.003 \\
\hline Height (cm) & $170 \pm 7(159-181)$ & $174 \pm 9(162-188)$ & 0.154 \\
\hline Weight (kg) & $71 \pm 10(53-82)$ & $75 \pm 13(53-92)$ & 0.309 \\
\hline Body mass index $\left(\mathrm{kg} / \mathrm{m}^{2}\right)$ & $25 \pm 4(19-32)$ & $25 \pm 4(19-31)$ & 0.862 \\
\hline Followup (years) & $1.1(1-1.3)$ & $1.3(1-1.9)$ & 0.636 \\
\hline
\end{tabular}

Values are mean \pm SD with ranges in parentheses.

Table 2. Radiographic characteristics of the two study groups

\begin{tabular}{|c|c|c|c|c|c|}
\hline \multirow[t]{2}{*}{ Parameter } & \multirow{2}{*}{$\begin{array}{l}\text { Nonoperative } \\
\text { group } \\
\text { Baseline }\end{array}$} & \multirow{2}{*}{$\begin{array}{l}\text { Operative } \\
\text { group } \\
\text { Baseline }\end{array}$} & \multirow[b]{2}{*}{ Postoperative } & \multicolumn{2}{|l|}{$\mathrm{p}$ value } \\
\hline & & & & $\begin{array}{l}\text { Baseline } \\
\text { versus baseline }\end{array}$ & $\begin{array}{l}\text { Baseline versus } \\
\text { postoperative }\end{array}$ \\
\hline Number of hips (patients) & $20(20)$ & $20(19)$ & $20(19)$ & - & - \\
\hline Alpha angle $\left(^{\circ}\right)$ & $65 \pm 10(46-91)$ & $73 \pm 12(55-91)$ & $53 \pm 6(42-63)$ & 0.022 & $<0.001$ \\
\hline Femoral torsion $\left({ }^{\circ}\right)$ & $14 \pm 10(-13$ to 29$)$ & $15 \pm 8(-6$ to 28$)$ & $14 \pm 6(-3$ to 28$)$ & 0.986 & 0.914 \\
\hline Lateral center-edge angle $\left(^{\circ}\right)$ & $32 \pm 8(17-48)$ & $32 \pm 9(25-63)$ & $29 \pm 7(22-47)$ & 0.967 & 0.002 \\
\hline Extrusion index $\left({ }^{\circ}\right)$ & $20 \pm 8(3-36)$ & $20 \pm 6(1-27)$ & $22 \pm 7(1-29)$ & 0.926 & $<0.001$ \\
\hline Acetabular index $\left({ }^{\circ}\right)$ & $1 \pm 8(-11$ to 19$)$ & $1 \pm 5(-9$ to 11$)$ & $2 \pm 5(-9$ to 9$)$ & 0.975 & 0.687 \\
\hline Number of hips with protrusio (\%) & 0 & $1(5)$ & $1(5)$ & 0.305 & 1 \\
\hline $\begin{array}{l}\text { Number of hips with positive crossover sign } \\
(\%)\end{array}$ & $14(70)$ & $13(65)$ & $10(50)$ & 0.639 & 0.18 \\
\hline $\begin{array}{l}\text { Number of hips with positive posterior wall } \\
\text { sign }(\%)\end{array}$ & $14(70)$ & $15(75)$ & $15(75)$ & 0.605 & 1 \\
\hline $\begin{array}{l}\text { Number of hips with positive ischial spine } \\
\text { sign }(\%)\end{array}$ & $7(35)$ & $7(35)$ & $7(35)$ & 1 & 1 \\
\hline Retroversion index $(\%)$ & $25 \pm 10(10-47)$ & $19 \pm 11(6-37)$ & $18 \pm 12(2-36)$ & 0.122 & 0.438 \\
\hline Neck-shaft angle $\left({ }^{\circ}\right)$ & $132 \pm 7(122-151)$ & $131 \pm 5(123-144)$ & $130 \pm 6(121-141)$ & 0.478 & 0.343 \\
\hline
\end{tabular}

Values are mean $\pm \mathrm{SD}$ with ranges in parentheses.

Table 3. Patient-reported outcomes of the two study groups at baseline and at 1-year followup

\begin{tabular}{|c|c|c|c|c|c|c|c|c|}
\hline \multirow[t]{2}{*}{ Score } & \multicolumn{2}{|c|}{ Nonoperative group } & \multicolumn{2}{|c|}{ Operative group } & \multicolumn{4}{|l|}{$\mathrm{p}$ value } \\
\hline & Baseline & Followup & Baseline & Followup & $\begin{array}{l}\text { Nonoperative } \\
\text { baseline versus } \\
\text { followup }\end{array}$ & $\begin{array}{l}\text { Operative baseline } \\
\text { versus followup }\end{array}$ & $\begin{array}{l}\text { Groups at } \\
\text { baseline }\end{array}$ & $\begin{array}{l}\text { Groups at } \\
\text { followup }\end{array}$ \\
\hline WOMAC (0-240) & $\begin{array}{l}49 \pm 46 \\
(1-161)\end{array}$ & $\begin{array}{l}44 \pm 49 \\
(0-164)\end{array}$ & $\begin{array}{l}59 \pm 40 \\
(5-108)\end{array}$ & $\begin{array}{l}31 \pm 40 \\
(0-153)\end{array}$ & 0.906 & 0.001 & 0.385 & 0.499 \\
\hline HOOS (0-100) & $\begin{array}{l}67 \pm 16 \\
(43-96)\end{array}$ & $\begin{array}{l}68 \pm 20 \\
(24-95)\end{array}$ & $\begin{array}{l}62 \pm 16 \\
(38-86)\end{array}$ & $\begin{array}{l}74 \pm 19 \\
(30-100)\end{array}$ & 0.828 & 0.004 & 0.406 & 0.329 \\
\hline mHHS (0-91) & $\begin{array}{l}61 \pm 20 \\
(13-91)\end{array}$ & $\begin{array}{l}72 \pm 16 \\
(38-91)\end{array}$ & $\begin{array}{l}57 \pm 17 \\
(38-88)\end{array}$ & $\begin{array}{l}71 \pm 15 \\
(35-91)\end{array}$ & 0.013 & 0.001 & 0.562 & 0.952 \\
\hline
\end{tabular}

Values are mean \pm SD with ranges in parentheses; WOMAC $=$ Western Ontario and McMaster Universities Osteoarthritis Index; HOOS $=$ Hip disability and Osteoarthritis Outcome Score; mHHS = modified Harris hip score. 
Table 4. Changes over time in combined acetabular and femoral dGEMRIC indices after surgery and nonoperative treatment

\begin{tabular}{|c|c|c|c|c|c|c|c|c|}
\hline \multirow[t]{2}{*}{ Region } & \multirow[t]{2}{*}{ Group } & \multirow[t]{2}{*}{ Time point } & \multirow{2}{*}{$\begin{array}{l}\text { Mean dGEMRIC } \\
\text { index }(\mathrm{ms})^{*}\end{array}$} & \multicolumn{5}{|l|}{$\mathrm{p}$ value } \\
\hline & & & & $\begin{array}{l}\text { Baseline versus } \\
\text { followup }\end{array}$ & $\begin{array}{l}\text { Groups at } \\
\text { baseline }\end{array}$ & $\begin{array}{l}\text { Groups at } \\
\text { followup }\end{array}$ & $\begin{array}{l}\text { Change } \\
\text { between groups }\end{array}$ & $\begin{array}{l}\text { Change } \\
\text { between region }\end{array}$ \\
\hline \multirow[t]{6}{*}{ Acetabulum } & Nonoperative & Baseline & $505 \pm 171$ & 0.006 & 0.472 & $<0.001$ & $<0.001$ & 0.739 \\
\hline & & Followup & $489 \pm 178$ & & & & & \\
\hline & & Change & $-16 \pm 101$ & & & & & \\
\hline & Operative & Baseline & $521 \pm 197$ & $<0.001$ & & & & 0.69 \\
\hline & & Followup & $424 \pm 165$ & & & & & \\
\hline & & Change & $-96 \pm 112$ & & & & & \\
\hline \multirow[t]{6}{*}{ Femur } & Nonoperative & Baseline & $462 \pm 137$ & $<0.001$ & 0.298 & $<0.001$ & $<0.001$ & \\
\hline & & Followup & $441 \pm 141$ & & & & & \\
\hline & & Change & $-21 \pm 83$ & & & & & \\
\hline & Operative & Baseline & $488 \pm 174$ & $<0.001$ & & & & \\
\hline & & Followup. & $392 \pm 125$ & & & & & \\
\hline & & Change & $-96 \pm 123$ & & & & & \\
\hline
\end{tabular}

* Values are mean \pm SD; means of peripheral and central regions of interest per hour position were used for calculation; for comparing changes over time between the acetabular and femoral cartilage, the difference between baseline and followup dGEMRIC indices was calculated at each clockface position; dGEMRIC $=$ delayed gadolinium-enhanced MRI of cartilage.

$36 \pm 8$ years versus $30 \pm 8$ years, $\mathrm{p}=0.026$; Table 1 ). The nonoperative group presented with a lower $\alpha$ angle $\left(65^{\circ} \pm 10^{\circ}\right.$ versus $73^{\circ} \pm 12^{\circ} ; \mathrm{p}=0.022$; Table 2$)$.

In the operative group, surgical hip dislocation $(\mathrm{n}=12$ [60\%]) or hip arthroscopy ( $\mathrm{n}=8$ [40\%]) was performed. The indication for arthroscopic surgery was the presence of anterosuperior bony deformities and associated collateral damage. More complex and global deformities were treated by means of an open surgical hip dislocation. Groups were comparable regarding demographic and radiographic characteristics (Table 5). Baseline dGEMRIC indices were comparable between arthroscopic and open treatments (Table 6). Their preoperative PROMs (WOMAC, HOOS, mHHS; Table 7) were comparable as well. Arthroscopic procedures included: femoral osteochondroplasty in all eight cases (100\%), acetabular rim trimming with labral refixation in three cases (38\%), and microfracturing in one case $(13 \%)$. Open procedures included femoral osteochondroplasty in all 12 cases (100\%), acetabular rim trimming with labral refixation in eight cases $(67 \%)$, acetabular rim trimming with labral reconstruction in two cases (17\%), and microfracturing in three cases $(25 \%)$. We compared mean acetabular and femoral dGEMRIC indices at baseline and 1 year after arthroscopic hip surgery versus surgical hip dislocation. Intraoperative assessment of chondral lesions was performed according to the Beck classification [3] and was reported in 18 (90\%) cases. Intraoperative Beck grades of cartilage lesions were documented according to their localization, namely in the anterosuperior (12-3 o'clock) and posterosuperior (9-12 o'clock) quadrants [48] (Fig. 3). There were 16 anterosuperior acetabular cartilage lesions: two hips with chondromalacia (no procedures performed), two hips with a debonding phenomenon (no procedures performed), 11 hips with a cleavage lesion (six cases [55\%] no procedure performed; two cases [22\%] débridement; three cases [33\%] débridement with microfracturing); one hip with a full-thickness defect (débridement and microfracturing). There were seven posterosuperior acetabular cartilage lesions: six hips with a cleavage lesion (three cases [50\%] no procedures performed; one case [17\%] débridement; two cases [33\%] débridement and microfracturing), one hip with a full-thickness defect (débridement and microfracturing).

Patients were clinically evaluated by one of three individuals (FS, $\mathrm{PCH}, \mathrm{MSH})$ not involved in the surgical care of the patients at baseline and after 1 year. This included thorough acquisition of the patient history, a goniometric measurement of the hip ROM, the evaluation of the anterior and posterior impingement tests [51], and the assessment of abductor strength. Substantial inter- and intraobserver agreements have been reported previously for ROM [20, 31, 55] and the anterior impingement test [30]. Patients completed WOMAC [5], HOOS [27], and mHHS [14] questionnaires at baseline and at the 1-year followup visit (Table 3).

Routine baseline and 1-year followup radiographic evaluation included a standardized AP pelvic radiograph and a cross-table view [51]. Coxometric parameters were assessed on the AP pelvic radiograph with validated computer software $\mathrm{Hip}^{2}$ Norm (University of Bern, Bern, Switzerland) by one of us (FS, not involved in the surgical treatment of the patients) $[47,50,57]$ : lateral center-edge 
Table 5. Demographic characteristics of patients undergoing arthroscopy (HAS) and surgical dislocation (SHD) of the hip

\begin{tabular}{|c|c|c|c|}
\hline Parameter & HAS & SHD & $\mathrm{p}$ value \\
\hline Number of patients (hips) & $8(8)$ & $11(12)$ & - \\
\hline Age (years) & $31 \pm 8(20-42)$ & $30 \pm 8(20-47)$ & 0.857 \\
\hline Number of hips with Tönnis osteoarthritis Grade $1(\%)$ & $4(50)$ & $5(42)$ & 0.714 \\
\hline Sex (\% [hips] women of all hips per group) & $2(25)$ & $4(33)$ & 0.690 \\
\hline Height $(\mathrm{cm})$ & $177 \pm 9(165-187)$ & $173 \pm 9(162-188)$ & 0.454 \\
\hline Weight (kg) & $83 \pm 7(71-92)$ & $71 \pm 13(53-90)$ & 0.068 \\
\hline Body mass index $\left(\mathrm{kg} / \mathrm{m}^{2}\right)$ & $27 \pm 3(23-31)$ & $24 \pm 3(19-29)$ & 0.055 \\
\hline Alpha angle $\left({ }^{\circ}\right)$ & $76 \pm 12(62-91)$ & $72 \pm 11(55-86)$ & 0.499 \\
\hline Lateral center-edge angle $\left({ }^{\circ}\right)$ & $28 \pm 4(25-35)$ & $35 \pm 10(26-63)$ & 0.053 \\
\hline Extrusion index $\left({ }^{\circ}\right)$ & $23 \pm 4(18-27)$ & $18 \pm 7(1-31)$ & 0.08 \\
\hline Acetabular index $\left({ }^{\circ}\right)$ & $4 \pm 5(-3$ to 11$)$ & $0 \pm 5(-9$ to 6$)$ & 0.119 \\
\hline Number of hips with protrusio (\%) & $0(0)$ & $1(8)$ & 0.402 \\
\hline Number of hips with positive crossover sign (\%) & $7(88)$ & $6(50)$ & 0.085 \\
\hline Number of hips with positive posterior wall sign (\%) & $7(88)$ & $8(67)$ & 0.292 \\
\hline Number of hips with positive ischial spine sign (\%) & $3(38)$ & $4(33)$ & 0.848 \\
\hline Retroversion index $(\%)$ & $19 \pm 9(6-30)$ & $19 \pm 14(6-37)$ & 0.924 \\
\hline Number of hips with femoral osteochondroplasty & $8(100)$ & $12(100)$ & 1 \\
\hline Number of hips with rim trimming and labral refixation & $3(38)$ & $8(67)$ & 0.199 \\
\hline Number of hips with rim trimming and labral reconstruction & $0(0)$ & $2(17)$ & 0.224 \\
\hline Number of hips with microfracturing & $1(13)$ & $3(25)$ & 0.494 \\
\hline
\end{tabular}

Values are mean $\pm \mathrm{SD}$ with ranges in parentheses.

Table 6. Changes over time in combined acetabular and femoral dGEMRIC indices after hip arthroscopy and surgical hip dislocation

\begin{tabular}{|c|c|c|c|c|c|c|c|c|}
\hline \multirow[t]{2}{*}{ Region } & \multirow[t]{2}{*}{ Group } & \multirow{2}{*}{$\begin{array}{l}\text { Time } \\
\text { point }\end{array}$} & \multirow{2}{*}{$\begin{array}{l}\text { Mean dGEMRIC } \\
\text { index }(\mathrm{ms})^{*}\end{array}$} & \multicolumn{5}{|l|}{$\mathrm{p}$ value } \\
\hline & & & & $\begin{array}{l}\text { Baseline versus } \\
\text { followup }\end{array}$ & $\begin{array}{l}\text { Groups at } \\
\text { baseline }\end{array}$ & $\begin{array}{l}\text { Groups at } \\
\text { followup }\end{array}$ & $\begin{array}{l}\text { Change } \\
\text { between groups }\end{array}$ & $\begin{array}{l}\text { Change } \\
\text { between region }\end{array}$ \\
\hline \multirow[t]{6}{*}{ Acetabulum } & \multirow{3}{*}{$\begin{array}{l}\text { Hip } \\
\quad \text { arthroscopy }\end{array}$} & Baseline & $520 \pm 167$ & \multirow[t]{3}{*}{$<0.001$} & \multirow[t]{6}{*}{0.576} & \multirow[t]{6}{*}{0.006} & \multirow[t]{6}{*}{0.143} & \multirow[t]{3}{*}{0.15} \\
\hline & & Followup & $448 \pm 145$ & & & & & \\
\hline & & Change & $-72 \pm 81$ & & & & & \\
\hline & \multirow{3}{*}{$\begin{array}{l}\text { Surgical hip } \\
\text { dislocation }\end{array}$} & Baseline & $521 \pm 216$ & \multirow[t]{3}{*}{$<0.001$} & & & & \multirow[t]{3}{*}{0.679} \\
\hline & & Followup & $408 \pm 177$ & & & & & \\
\hline & & Change & $-113 \pm 127$ & & & & & \\
\hline \multirow[t]{6}{*}{ Femur } & \multirow{3}{*}{$\begin{array}{l}\text { Hip } \\
\text { arthroscopy }\end{array}$} & Baseline & $478 \pm 157$ & \multirow[t]{3}{*}{$<0.001$} & \multirow[t]{6}{*}{0.834} & \multirow[t]{6}{*}{0.008} & \multirow[t]{6}{*}{0.002} & \\
\hline & & Followup & $417 \pm 135$ & & & & & \\
\hline & & Change & $-61 \pm 89$ & & & & & \\
\hline & \multirow{3}{*}{$\begin{array}{l}\text { Surgical hip } \\
\text { dislocation }\end{array}$} & Baseline & $495 \pm 185$ & \multirow[t]{3}{*}{$<0.001$} & & & & \\
\hline & & Followup. & $375 \pm 115$ & & & & & \\
\hline & & Change & $-120 \pm 137$ & & & & & \\
\hline
\end{tabular}

* Values are mean $\pm \mathrm{SD}$; means of peripheral and central regions of interest per hour position were used for calculation; for comparing changes over time between the acetabular and femoral cartilage, the difference between baseline and followup dGEMRIC indices was calculated at each clockface position; dGEMRIC $=$ delayed gadolinium-enhanced MRI of cartilage.

angle, extrusion index, acetabular index, crossover sign, posterior wall sign, retroversion index, and neck shaft angle. The $\alpha$ angle was measured on radial MR images [45]. Femoral torsion was measured according to Murphy et al. [32] on proximal axial MR images through the femoral head and the center of the base of the femoral neck relative to the orientation of the distal femoral condyles. Presence or absence of the ischial spine sign [23] and protrusio acetabuli [49] was evaluated conventionally on AP pelvic views. Radiographic parameters between 
Table 7. Patient-reported outcomes and dGEMRIC indices of patients undergoing hip arthroscopy (HAS) and surgical hip dislocation (SHD) at baseline and at 1-year followup

\begin{tabular}{|c|c|c|c|c|c|c|c|c|}
\hline \multirow[t]{2}{*}{ Parameter } & \multicolumn{2}{|l|}{ HAS } & \multicolumn{2}{|l|}{ SHD } & \multicolumn{4}{|l|}{$\mathrm{p}$ value } \\
\hline & Baseline & Followup & Baseline & Followup & $\begin{array}{l}\text { HAS baseline } \\
\text { versus followup }\end{array}$ & $\begin{array}{l}\text { SHD baseline } \\
\text { versus followup }\end{array}$ & $\begin{array}{l}\text { Groups at } \\
\text { baseline }\end{array}$ & $\begin{array}{l}\text { Groups at } \\
\text { followup }\end{array}$ \\
\hline WOMAC (0-240) & $\begin{array}{l}54 \pm 38 \\
(10-93)\end{array}$ & $\begin{array}{l}49 \pm 53 \\
(0-153)\end{array}$ & $\begin{array}{l}62 \pm 43 \\
(5-108)\end{array}$ & $\begin{array}{l}20 \pm 24 \\
(2-68)\end{array}$ & 0.043 & 0.009 & 0.806 & 0.231 \\
\hline HOOS $(0-100)$ & $\begin{array}{l}59 \pm 22 \\
(38-81)\end{array}$ & $\begin{array}{l}63 \pm 23 \\
(30-100)\end{array}$ & $\begin{array}{l}63 \pm 15 \\
(41-86)\end{array}$ & $\begin{array}{l}81 \pm 12 \\
(62-96)\end{array}$ & 0.107 & 0.015 & 0.765 & 0.033 \\
\hline mHHS (0-91) & $\begin{array}{l}51 \pm 11 \\
(38-67)\end{array}$ & $\begin{array}{l}61 \pm 18 \\
(35-91)\end{array}$ & $\begin{array}{l}60 \pm 19 \\
(39-88)\end{array}$ & $\begin{array}{l}78 \pm 9 \\
(61-87)\end{array}$ & 0.135 & 0.005 & 0.375 & 0.012 \\
\hline
\end{tabular}

Values are mean \pm SD with ranges in parentheses; dGEMRIC $=$ delayed gadolinium-enhanced MRI of cartilage; WOMAC $=$ Western Ontario and McMaster Universities Osteoarthritis Index; HOOS = Hip disability and Osteoarthritis Outcome Score; mHHS = modified Harris hip score.

nonoperative and operative groups did not differ except for the $\alpha$ angle (mean $65^{\circ} \pm 10^{\circ}$ versus $73^{\circ} \pm 12^{\circ}$, $\mathrm{p}=0.022$ ).

All patients underwent indirect MR arthrography with intravenous administration of Gd-DTPA2-(Magnevist $0.2 \mathrm{mmol} / \mathrm{ml} / \mathrm{kg}$; Bayer, Leverkusen, Germany) to obtain morphologic and dGEMRIC images according to a standardized protocol. A single 3.0-T scanner (Trio; Siemens, Erlangen, Germany) with a flexible surface coil was used. After injection of contrast agent, patients were asked to walk around for 15 minutes and then to wait for a further 5 to 30 minutes to facilitate adequate penetration of gadolinium into the cartilage. In addition to the multiplanar protocol (aquisition time [AT] of 20 minutes), a two-dimensional radial proton density-weighted (PD-w) sequence (repetition time [TR]/echo time [TE], 1500/18 ms, slice thickness of $4 \mathrm{~mm}, 160 \times 160-\mathrm{mm}$ field of view, a matrix size of $448 \times 317$, AT of 4:30 minutes for 14 slices), which was oriented along the axis of the femoral neck, was obtained for morphologic assessment [28]. Acquisition of the T1 map for dGEMRIC measurements started 45 to 70 minutes after intravenous contrast injection. Similar to previous investigations, a dual-flip angle three-dimensional (3-D) gradient-echo technique was used (TR/TE, 15/ $3.3 \mathrm{~ms}$, flip angles of $4^{\circ}$ and $24^{\circ}$, slice thickness of $0.78 \mathrm{~mm}, 160 \times 160$-mm field of view, a matrix size of $192 \times 192$, isotropic voxel size of $0.78 \mathrm{~mm}^{3}$, AT of 8.46 minutes for 128 slices) [8, 16-18, 25, 29, 41].

Commercially available software, Osirix (Version 6.0; Geneva, Switzerland [38]), was used for reformation of 12 radial slices from the 3-D data set and for manual measurement of dGEMRIC indices by one author (FS) with 3 years of experience in hip MRI (Fig. 3A). The orientation of the reformatted images was identical to the morphologic two-dimensional radial PD-w images to enable direct comparison between both sequences. This provides a reasonable approximation of the majority of both joint surfaces, because a full perpendicular assessment of the entire acetabular circumference is technically not feasible as a result of variants in the size and shape of the lunate surface [44]. Acetabular and femoral cartilage layers were assessed separately. On the acetabular side, dGEMRIC indices were measured on 10 "full-hour" positions except for the 5 o'clock and 6 o'clock positions of the inferior acetabular notch. On the femoral side, all 12 "fullhour" positions were measured. The teardrop figure was used as an anatomic landmark for the acetabular 6 o'clock position (Fig. 3B), whereas the most prominent appearance of the greater trochanter was used to define the femoral 12 o'clock position (Fig. 3C) [28].

Baseline and followup dGEMRIC images were evaluated at the same time with direct comparison of morphologic radial PD-w slices. The followup morphologic scans were used to define the acetabular (Fig. 4A) and femoral (Fig. 4B) cartilage extension for both dGEMRIC measurements to minimize variations in ROI placement resulting from femoral osteochondroplasty and rim trimming. Articular cartilage layers were divided into central and peripheral ROIs resulting in 20 ROIs per hip on the acetabular side and 24 ROIs per hip on the femoral side. The margins for the acetabular cartilage were the rim on the lateral side and the acetabular fossa on the medial side (Fig. 4C). The margins for the femoral cartilage were the head-neck junction on the lateral side and the fovea capitis femoris on the medial side (Fig. 4D). These ROIs were defined in the same manner on the baseline dGEMRIC reformats within the acetabular (Fig. 4E) and femoral cartilage (Fig. 4F), respectively. The T1 value (dGEMRIC index) for each ROI at each time point was calculated by the software and stored in our database.

Two different observers (FS, MSH) measured the dGEMRIC indices independently from each other and on 

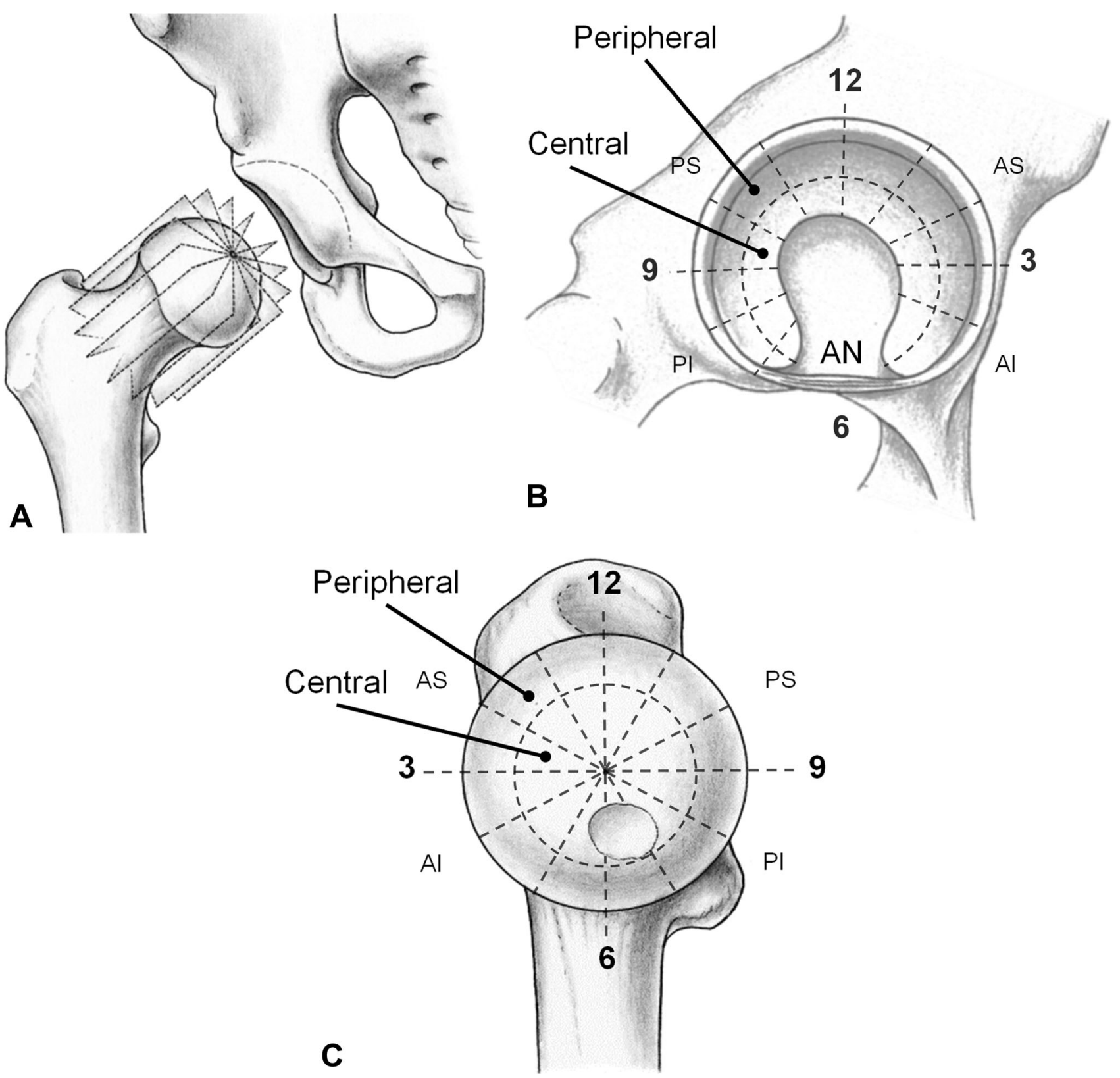

Fig. 3A-C (A) The reformatted radial slices around the femoral neck axis are shown. (B) The acetabular 6 o'clock reference was defined in the acetabular notch (AN). The cartilaginous area of the lunate surface was further subdivided into peripheral and central regions. (C) The femoral 12 o'clock position was defined by the most prominent portion of the greater trochanter. Analogously, the femoral cartilage was subdivided into a central and a peripheral portion.

two different time points on a random sample of 30 hips. The measurements were compared using the intraclass correlation coefficient. We found an interobserver reproducibility of 0.772 (95\% confidence interval [CI], 0.5750.885 ) for the first measurement and 0.895 (95\% CI, 0.7910.949 ) for the second. The intraobserver reliability was
$\mathrm{AS}=$ anterosuperior quadrant, $\mathrm{PS}=$ postersuperior quadrant, $\mathrm{AI}=$ anteroinferior quadrant, $\mathrm{PI}=$ posteroinferior quadrant. Reprinted with kind permission from Springer Science + Business Media: Steppacher SD, Tannast M, Werlen S, Siebenrock KA. Femoral morphology differs between deficient and excessive acetabular coverage. Clin Orthop Relat Res. 2008;466:782-790; 3A, B.

0.792 (95\% CI, 0.608-0.895) for observer 1 and 0.978 (95\% CI, 0.954-0.989) for observer 2.

To answer question one, we compared the dGEMRIC index between baseline and followup measurements between the two study groups for the combined acetabular and combined femoral cartilage only. Furthermore, we 
Fig. 4A-F The manual placement of regions of interest with help of (A-B) followup morphologic images to define cartilage extension was performed simultaneously on $(\mathbf{C}$ D) followup and (E-F) baseline dGEMRIC images. (A, C, E) The margins for the acetabular cartilage were the rim on the lateral side and the acetabular fossa on the medial side. Cartilage areas were subdivided into (p) peripheral and (c) central regions. (B, D, F) The margins for the femoral cartilage were the head-neck junction on the lateral side and the fovea capitis femoris on the medial side. Cartilage areas were subdivided into (p) peripheral and (c) central regions.
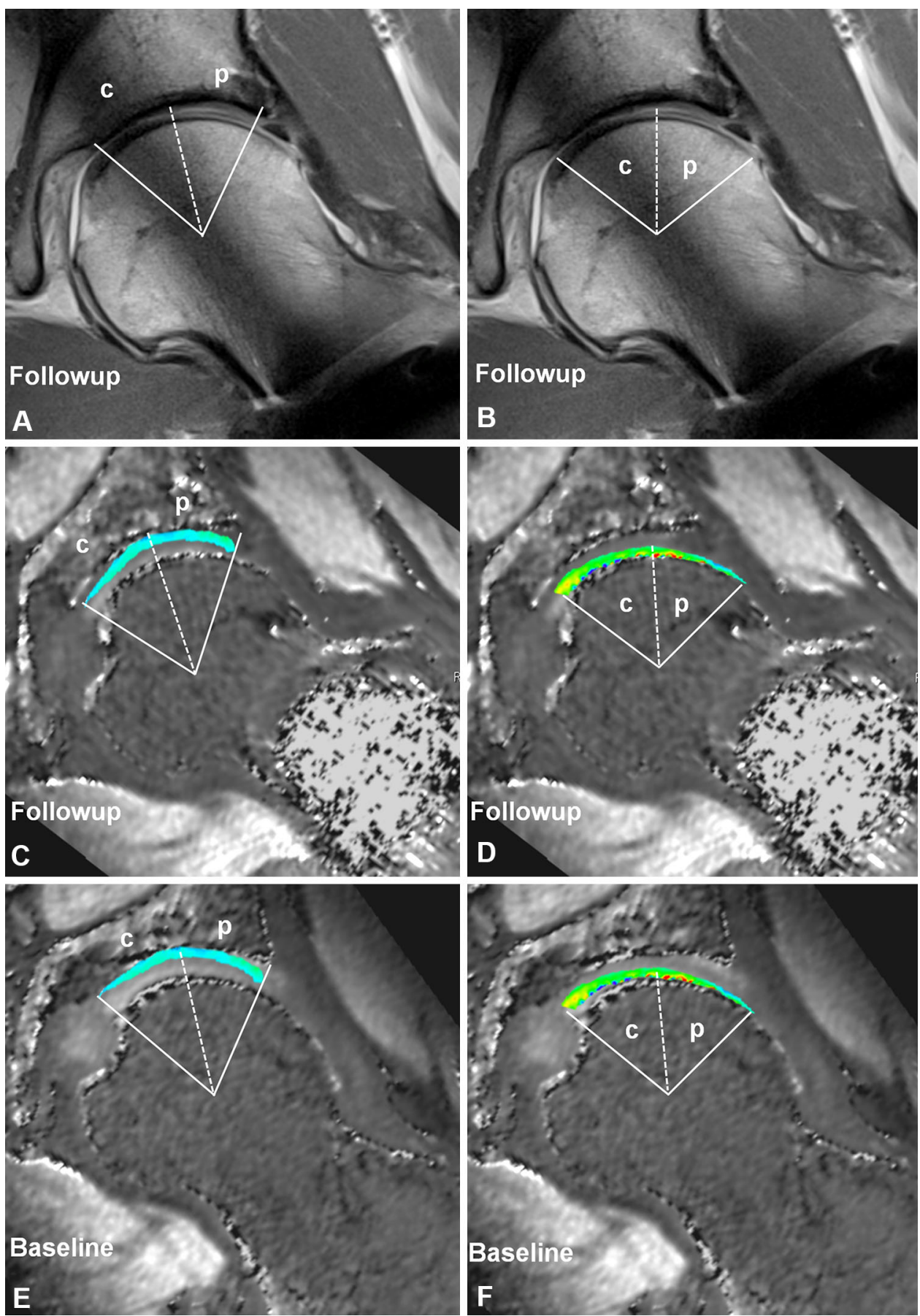

compared mean acetabular and femoral dGEMRIC indices at baseline and 1 year after arthroscopic hip surgery versus surgical hip dislocation.

To answer question two, we compared the acetabular and femoral dGEMRIC indices of all 44 peripheral and central ROIs around the clockface for both groups over time.

To answer question three, we correlated the baseline dGEMRIC index with the change in the three assessed PROMs. In addition, we subdivided the operative group into two subgroups, similarly to previous studies $[9,26]$ : one with a "normal" and one with a "pathologic" dGEMRIC index. The threshold for an allocation to these subgroups was calculated by subtracting the SD from the mean dGEMRIC index of the entire joint per patient (332 ms). Differences in PROMs were then calculated for the two subgroups.

To answer question four, we compared the dGEMRIC index for the antero- and posterosuperior quadrants with the actual chondral damage at these locations. For the 
Table 8. Changes over time in regional acetabular and femoral dGEMRIC indices after surgery and nonoperative treatment

\begin{tabular}{|c|c|c|c|c|c|}
\hline \multirow[t]{2}{*}{ Groups } & \multirow[t]{2}{*}{ Regions } & & \multicolumn{3}{|c|}{ Number of regions $(\%)$ with differences $(\mathrm{p}<0.05)$ in dGEMRIC indices } \\
\hline & & & Baseline versus followup & Groups at baseline & Groups at followup \\
\hline \multirow[t]{4}{*}{ Nonoperative } & \multirow[t]{2}{*}{ Acetabulum } & Peripheral & $1 / 10(10)$ & $0 / 10(0)$ & $0 / 10(0)$ \\
\hline & & Central & $0 / 10(0)$ & $0 / 10(0)$ & $0 / 10(0)$ \\
\hline & \multirow[t]{2}{*}{ Femur } & Peripheral & $2 / 12(17)$ & $0 / 12(0)$ & $3 / 12(25)$ \\
\hline & & Central & $1 / 12(8)$ & $0 / 12(0)$ & $1 / 12(8)$ \\
\hline \multirow[t]{4}{*}{ Operative } & \multirow[t]{2}{*}{ Acetabulum } & Peripheral & 10/10 (100) & & \\
\hline & & Central & $10 / 10(100)$ & & \\
\hline & \multirow[t]{2}{*}{ Femur } & Peripheral & 11/12 (92) & & \\
\hline & & Central & 12/12 (100) & & \\
\hline
\end{tabular}

dGEMRIC $=$ delayed gadolinium-enhanced MRI of cartilage.

anterosuperior quadrant, patients were categorized as "disease-positive" when having cleavage lesions or fullthickness defects of the cartilage. For the posterosuperior quadrant, patients were categorized as "disease-positive" when having any chondral pathology.

Normal distribution was tested with the KolmogorovSmirnov test for continuous parameters. Normally distributed data were compared among and within groups with paired and unpaired Student's t-test. Nonnormally distributed data were compared among groups and within groups with the Mann-Whitney U-test for unpaired and Wilcoxon rank-sum test for paired variables. Categorical variables were compared with the chi square test. We used a linear regression analysis for correlation between change in PROMs and the baseline dGEMRIC index. We used planar maps for a more intuitive illustration of the dGEMRIC changes. The regionally distribution of dGEMRIC indices over the lunate surface and femoral head were illustrated using surface color plots. For smooth mapping, the dGEMRIC indices of each ROI were interpolated in a bilinear fashion using MATLAB (The MathWorks, Inc, Natick, MA, USA). High indices were colored blue estimating high GAG content, whereas conversely, low indices were colored red.

\section{Results}

Although both the operative and the nonoperative groups experienced decreased dGEMRIC indices, the declines were more pronounced in the operative group. The decrease was $-96 \pm 112 \mathrm{~ms}$ versus $-16 \pm 101 \mathrm{~ms}$ on the acetabular side and $-96 \pm 123$ versus $-21 \pm 83 \mathrm{~ms}$ on the femoral side in the operative and the nonoperative groups, respectively ( $\mathrm{p}<0.001$ for both). For the study group undergoing operative treatment for FAI, the mean acetabular dGEMRIC index decreased from $521 \pm 197 \mathrm{~ms}$ to $424 \pm 165 \mathrm{~ms} \quad(\mathrm{p}<0.001)$ and the mean femoral dGEMRIC index decreased from $488 \pm 174 \mathrm{~ms}$ to $392 \pm 125 \mathrm{~ms}(\mathrm{p}<0.001$; Table 4). For the control group undergoing nonoperative treatment for FAI, the mean acetabular dGEMRIC index decreased from $505 \pm 171 \mathrm{~ms}$ to $489 \pm 178 \mathrm{~ms} \quad(\mathrm{p}=0.006)$ and the mean femoral dGEMRIC index decreased from $462 \pm 137 \mathrm{~ms}$ to $441 \pm 141 \mathrm{~ms}(\mathrm{p}<0.001$; Table 4). Although both the group undergoing hip arthroscopy and the group undergoing surgical hip dislocation experienced decreased dGEMRIC indices, the decline in femoral dGEMRIC indices was more pronounced in hips after surgical hip dislocation $(-120 \pm 137 \mathrm{~ms}$ versus $-61 \pm 89 \mathrm{~ms}$, $\mathrm{p}=0.002$; Table 6).

In the operative group, a drop in dGEMRIC indices was observed in all 20 acetabular and in 23 of 24 femoral clockface positions at the 1-year followup (Table 8). Cumulative means of regional dGEMRIC indices at baseline and at 1-year followup are visualized (Fig. 5) for the operative group. In the nonoperative group a significant decline in dGEMRIC indices was observed in one of 20 acetabular and in three of 24 femoral clockface positions at the 1-year followup (Table 8). Cumulative means of regional dGEMRIC indices at baseline and at 1-year followup are visualized (Fig. 6) for the nonoperative group.

Although changes in WOMAC correlated with the baseline dGEMRIC indices in the operative group, no correlations were found for the HOOS and mHHS (Table 9). The strongest correlation was found between the change in the WOMAC score and the baseline dGEMRIC indices for the entire joint $(\mathrm{R}=0.788$; 95\% CI, 0.716 $0.858 ; \mathrm{p}<0.001 ;$ Fig. 7 ). In the nonoperative group no correlations were found between the baseline dGEMRIC index and the change in the WOMAC, HOOS, or mHHS. We found greater improvement in the WOMAC score for patients with combined acetabular and femoral dGEMRIC indices $\geq 332 \mathrm{~ms}($ Group 2) than $<332 \mathrm{~ms}$ (Table 10). 

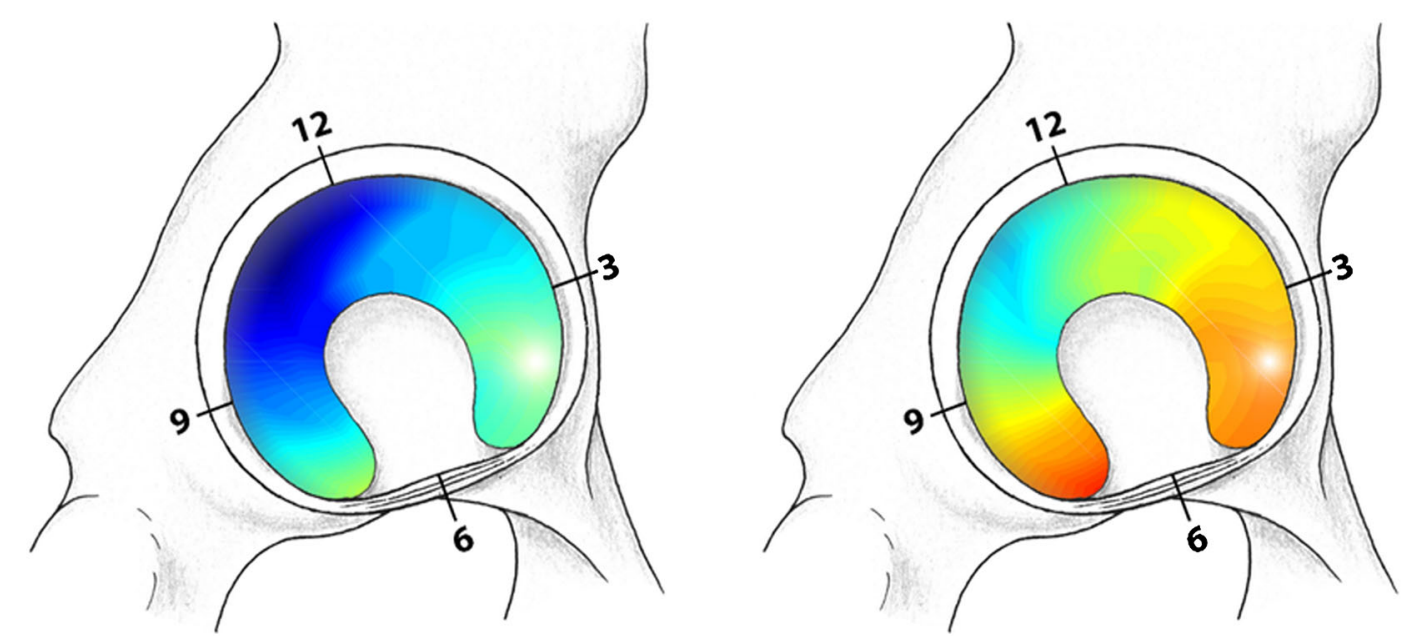

\section{Operative}

\section{Baseline}

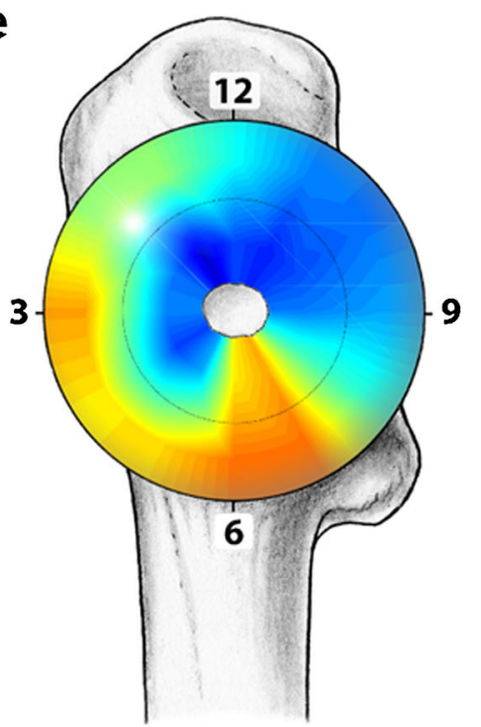

Operative Followup

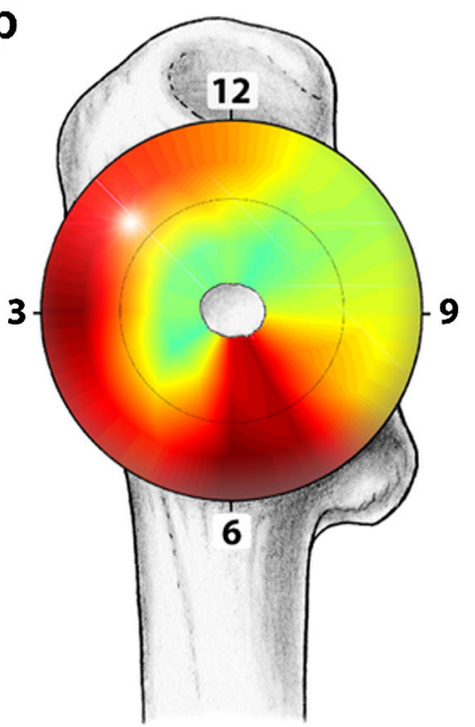

600

550

500

300

Fig. 5 This figure shows mapping of the regional distribution of the dGEMRIC values for the group undergoing surgical treatment for FAI at baseline (left) and 1-year followup (right). The planar maps indicate uniform decline in dGEMRIC indices after FAI surgery.

There was no such difference for the HOOS and the mHHS (Table 10).

In the posterosuperior quadrant, the dGEMRIC index was higher $(592 \pm 203 \mathrm{~ms}$ versus $444 \pm 205 \mathrm{~ms}$; $\mathrm{p}<0.001$ ) for patients with intact cartilage compared with hips with chondral pathologies (Table 11). There was no such difference for the anterosuperior quadrant (Table 11).

\section{Discussion}

There is sparse information on the prognostic value of the dGEMRIC technique in patients undergoing surgical treatment for FAI despite its known predictive value in the surgical treatment of dysplastic hips $[10,25]$
(Table 12). Particularly, there is a lack of knowledge on the biochemical behavior of the articular cartilage after surgery over time and in comparison to the natural course of patients with FAI. To the best of our knowledge, this is the first prospective, longitudinal study on dGEMRIC in patients with FAI with a nonrandomized control group of patients who did not undergo jointpreserving surgery. We found that the dGEMRIC index decreased to a substantially higher degree in operatively treated patients with FAI compared with nonoperative management at 1-year followup. The baseline dGEMRIC index correlated with the improvement in the WOMAC score 1 year postoperatively. The dGEMRIC index was able to depict early chondral degenerations in the posterosuperior quadrant. 

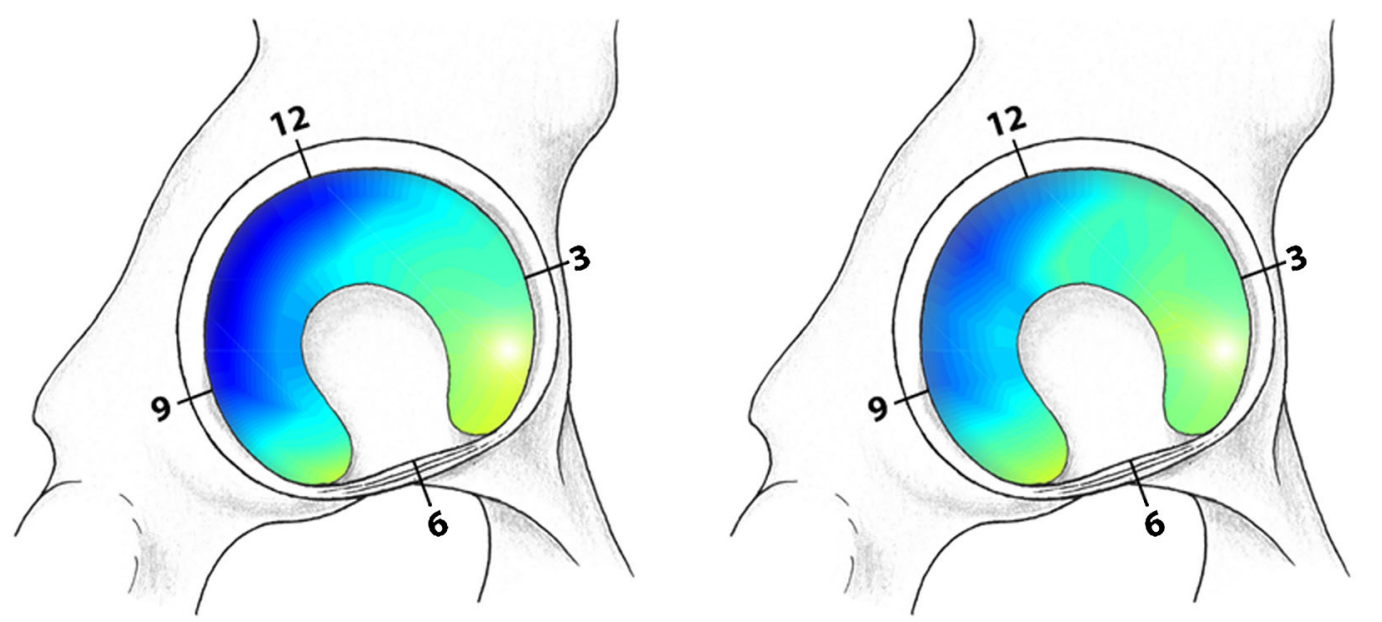

\section{Nonoperative} Baseline

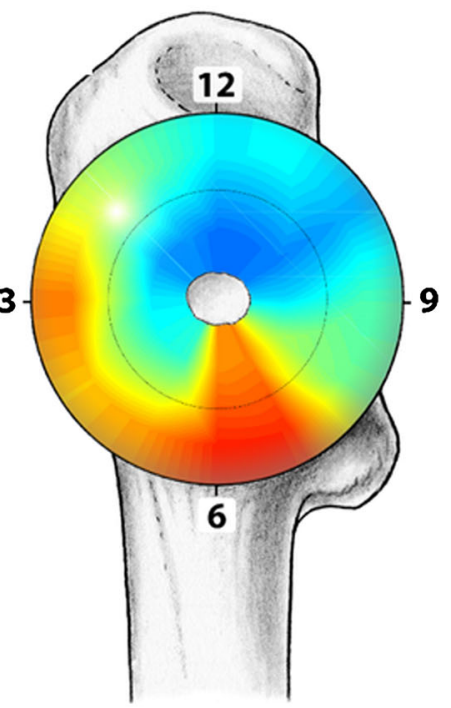

Nonoperative Followup

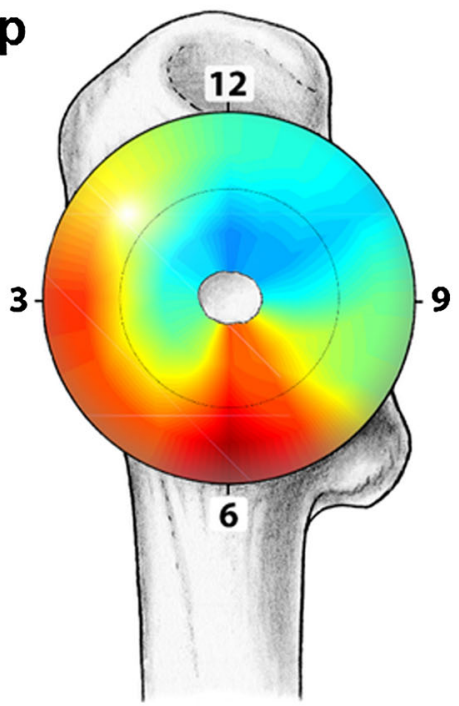

600

550

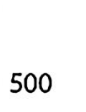

Fig. 6 Mapping of the regional distribution of the dGEMRIC values for the nonoperatively treated hips is shown, which indicates no uniform decline in dGEMRIC indices.

This study has several limitations. This 1-year followup study is a first prespecified institutional review board-approved interim analysis. Further 3-year and 5-year followup is planned in this patient cohort. First, the sample size is limited. This was primarily based on the power analysis for our main research question. However, the study is underpowered to investigate other factors such as the subtype and severity of FAI morphology in a multivariate analysis fashion. More patients were enrolled in the final study group to perform further subgroup analyses, which were beyond of the scope of this preliminary study.

Second, besides the lack of differences in most of the demographic and radiographic factors, the two study groups differed in terms of sex, age (Table 1). There were more women in the nonoperative group than in the operative group, subjects were older in the conservatively treated group. Furthermore $\alpha$ angles were lower (Table 2).

These three factors can potentially influence the results in the FAI treatment $[2,33,43]$. Furthermore, these factors can affect biochemical cartilage properties as assessed with dGEMRIC. Although the higher prevalence of women and higher age could negatively influence biochemical cartilage properties in the control group and thus predispose to degenerative disease, the control group also demonstrated a lower $\alpha$ angle, which is associated with better joint survival [59]. Nevertheless, we found neither a preoperative difference in the PROMs (Table 3) nor a difference in the baseline dGEMRIC value (Table 4) for the two groups. Third, dGEMRIC is a rather complex MRI technique that can be influenced by the patient's body mass index, the 
Table 9. Correlation between baseline dGEMRIC indices and change in patient-reported outcome measures

\begin{tabular}{|c|c|c|c|}
\hline Parameter & Equation & $\mathrm{R} / \mathrm{R}^{2}$ & $\mathrm{p}$ value \\
\hline Change of WOMAC versus dGEMRIC indices of entire joint & $Y=40.106-0.154 * X$ & $0.788 / 0.621$ & $<0.001$ \\
\hline $\begin{array}{l}\text { Change of WOMAC versus dGEMRIC indices of entire } \\
\text { acetabulum }\end{array}$ & $\mathrm{Y}=34.897-0.141 * \mathrm{X}$ & $0.774 / 0.6$ & $<0.001$ \\
\hline $\begin{array}{l}\text { Change of WOMAC versus central, posterosuperior }\left(11^{\circ}-9^{\circ}\right) \\
\text { acetabular dGEMRIC indices }\end{array}$ & $\mathrm{Y}=33.44-0.126^{*} \mathrm{X}$ & $0.772 / 0.595$ & $<0.001$ \\
\hline $\begin{array}{l}\text { Change of WOMAC versus central, anterosuperior }\left(1^{\circ}-3^{\circ}\right) \\
\text { acetabular dGEMRIC indices }\end{array}$ & $\mathrm{Y}=38.493-0.155^{*} \mathrm{X}$ & $0.759 / 0.576$ & 0.001 \\
\hline $\begin{array}{l}\text { Change of WOMAC versus peripheral, posterosuperior }\left(11^{\circ}-\right. \\
\left.9^{\circ}\right) \text { acetabular dGEMRIC indices }\end{array}$ & $\mathrm{Y}=28.868-0.113^{*} \mathrm{X}$ & $0.711 / 0.505$ & 0.003 \\
\hline $\begin{array}{l}\text { Change of WOMAC versus peripheral, anterosuperior }\left(1^{\circ}-3^{\circ}\right) \\
\text { acetabular dGEMRIC indices }\end{array}$ & $\mathrm{Y}=23.124-0.125^{*} \mathrm{X}$ & $0.668 / 0.447$ & 0.006 \\
\hline Change of HOOS versus dGEMRIC indices of entire joint & $\mathrm{Y}=-8.767+5.117 \mathrm{E}-02 * \mathrm{X}$ & $0.548 / 0.301$ & 0.065 \\
\hline $\begin{array}{l}\text { Change of HOOS versus dGEMRIC indices of entire } \\
\text { acetabulum }\end{array}$ & $\mathrm{Y}=-6.308+4.529 \mathrm{E}-02 * \mathrm{X}$ & $0.524 / 0.274$ & 0.081 \\
\hline $\begin{array}{l}\text { Change of HOOS versus central, posterosuperior }\left(11^{\circ}-9^{\circ}\right) \\
\text { acetabular dGEMRIC indices }\end{array}$ & $\mathrm{y}=-4.501+3.824 \mathrm{E}-02 * \mathrm{x}$ & $0.523 / 0.273$ & 0.081 \\
\hline $\begin{array}{l}\text { Change of HOOS versus peripheral, posterosuperior }\left(11^{\circ}-9^{\circ}\right) \\
\text { acetabular dGEMRIC indices }\end{array}$ & $\mathrm{y}=-5.794+3.913 \mathrm{E}-02 * x$ & $0.511 / 0.261$ & 0.09 \\
\hline $\begin{array}{l}\text { Change of HOOS versus central, anterosuperior }\left(1^{\circ}-3^{\circ}\right) \\
\text { acetabular dGEMRIC indices }\end{array}$ & $\mathrm{y}=-5.904+4.653 \mathrm{E}-02 * \mathrm{x}$ & $0.495 / 0.245$ & 0.102 \\
\hline $\begin{array}{l}\text { Change of HOOS versus peripheral, anterosuperior }\left(1^{\circ}-3^{\circ}\right) \\
\text { acetabular dGEMRIC indices }\end{array}$ & $\mathrm{Y}=-2.673+4.079 \mathrm{E}-02 * \mathrm{X}$ & $0.404 / 0.163$ & 0.193 \\
\hline $\begin{array}{l}\text { Change of mHHS versus central, posterosuperior }\left(11^{\circ}-9^{\circ}\right) \\
\text { acetabular dGEMRIC indices }\end{array}$ & $\mathrm{Y}=1.456+2.636 \mathrm{E}-02 * \mathrm{X}$ & $0.372 / 0.138$ & 0.172 \\
\hline Change of mHHS versus dGEMRIC indices of entire joint & $\mathrm{Y}=0.994+3.032 \mathrm{E}-02 * \mathrm{X}$ & $0.358 / 0.128$ & 0.19 \\
\hline $\begin{array}{l}\text { Change of mHHS versus dGEMRIC indices of entire } \\
\text { acetabulum }\end{array}$ & $\mathrm{Y}=2.453+2.683 \mathrm{E}-02 * \mathrm{X}$ & $0.341 / 0.116$ & 0.213 \\
\hline $\begin{array}{l}\text { Change of mHHS versus peripheral, posterosuperior }\left(11^{\circ}-9^{\circ}\right) \\
\text { acetabular dGEMRIC indices }\end{array}$ & $\mathrm{Y}=2.771+0.023 * \mathrm{X}$ & $0.334 / 0.111$ & 0.224 \\
\hline $\begin{array}{l}\text { Change of mHHS versus central, anterosuperior }\left(1^{\circ}-3^{\circ}\right) \\
\text { acetabular dGEMRIC indices }\end{array}$ & $\mathrm{Y}=3.571+2.595 \mathrm{E}-02 * \mathrm{X}$ & $0.293 / 0.086$ & 0.289 \\
\hline $\begin{array}{l}\text { Change of mHHS versus peripheral, anterosuperior }\left(1^{\circ}-3^{\circ}\right) \\
\text { acetabular dGEMRIC indices }\end{array}$ & $\mathrm{Y}=6.876+1.935 \mathrm{E}-02 * \mathrm{X}$ & $0.239 / 0.057$ & 0.39 \\
\hline
\end{tabular}

dGEMRIC = delayed gadolinium-enhanced MRI of cartilage; WOMAC = Western Ontario and McMaster Universities Osteoarthritis Index; HOOS = Hip disability and Osteoarthritis Outcome Score; mHHS = modified Harris hip score.

degree of physical activity, and variations in delay between injection of contrast agent and imaging [52, 53]. The prospective design of our study and the use of a single scanner allowed the best possible standardization of the imaging technique. Fourth, the used protocol did not include B1 maps to correct for magnetic field inhomogeneities, which can affect dGEMRIC indices, especially at 3.0 T [40]. This drawback should not jeopardize our conclusions to a substantial degree because they were uniformly present in both groups at each time point. Fifth, both open and arthroscopic procedures were used. However, the rationale for the choice of the surgical approach was standardized according to previously published algorithms [39, 42]. Indications for arthroscopic surgery included the presence of anterosuperior bony deformities and associated collateral damage. Complex and global deformities were treated by means of open surgical hip dislocation. Femoral asphericities reaching over the retinacular vessels or in the posterior aspect of the femoral head were treated with open resection. There was no difference between the decline in mean acetabular dGEMRIC indices from baseline to the 1-year followup. However, the decrease in mean femoral dGMERIC indices was more pronounced in patients undergoing surgical hip dislocation (Table 6). This may be explained by the extent of open surgery despite the use of an intermuscular and internerval approach, which reportedly does not affect the joint surrounding soft tissues [13].

The decrease in dGMERIC indices from baseline to the 1-year followup was more pronounced in the operative group than in the nonoperative group. We found a decrease in the dGEMRIC index (indicating more cartilage 
degeneration) in the operated group at 1-year followup (Fig. 5) despite the improvement of all PROMs (Table 3). Even if we observed a decrease in the dGEMRIC index in the nonoperative group, this drop was less pronounced, although two of three PROMs did not improve (Table 3). This paradox between reduced pain/improved function and a radiographic deterioration of the cartilage based on the dGEMRIC index has already been described earlier in hips undergoing PAO for hip dysplasia [16, 17]. Furthermore, Hingsammer et al. could not detect any radiographic or MR

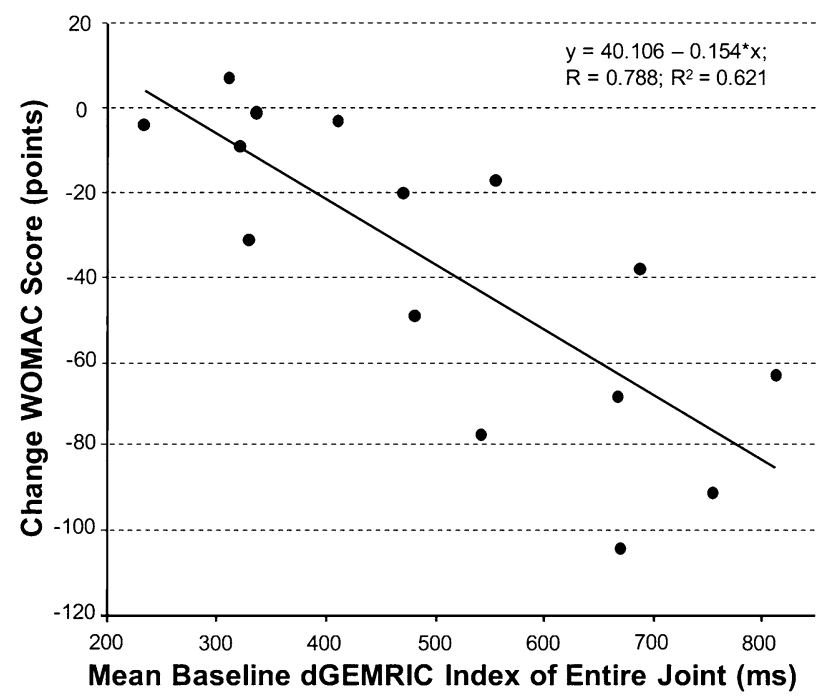

Fig. 7 The linear correlation between the baseline dGEMRIC index and the improvement of the Western Ontario and McMaster Universities Osteoarthritis Index (WOMAC), score is shown. morphologic signs of osteoarthritis progression at the 2year followup. At the 2-year followup, the same authors $[16,17]$ observed partial recovery of the biochemical properties. The reason for such an unexpected phenomenon remains unclear. Potential explanations are postsurgical inflammation and/or alteration in mechanical loading, which can directly influence the GAG content of the cartilage [15, 37]. Another explanation could be the slow regeneration potential of the bradytrophic articular cartilage covering several years. Our study differs from those of Hingsammer et al. $[16,17]$ in terms of the surgical procedure performed (extraarticular [PAO without capsulotomy] versus intraarticular [surgical hip dislocation/ hip arthroscopy]) and the underlying pathomechanism (static overload in dysplastic hips versus dynamic stress in impingement hips). Theoretically, the surgical intervention itself can alter the dGEMRIC properties of the cartilage by induction of the inflammation cascade, iatrogenic injury of the cartilage, surgical overcorrection, and/or alteration of joint biomechanics.

To the best of our knowledge, the natural course of FAI in symptomatic patients has not been monitored previously with morphologic MRI or the dGEMRIC technique. By contrast a study involving 723 subjects (1411 hips, "CHECK" cohort) with early symptomatic osteoarthritis of the knee or hip could show that $\alpha$ angles $>60^{\circ} />83^{\circ}$ resulted in an adjusted odds ratio of 3.67 and 9.66 for endstage radiographic osteoarthritis and THA, respectively, within 5 years [1]. Our findings in this small sample of

Table 10. Operative group was divided according to combined baseline acetabular and femoral dGEMRIC cutoff of $332 \mathrm{~ms}$ (combined acetabular and femoral dGEMRIC index-1 SD)

\begin{tabular}{|c|c|c|c|c|c|}
\hline \multirow[t]{2}{*}{ Parameter } & \multicolumn{2}{|l|}{ Operative groups } & \multicolumn{3}{|l|}{$\mathrm{p}$ values } \\
\hline & $\begin{array}{l}\text { Group } 1 \\
(\text { dGEMRIC }<332 \mathrm{~ms})\end{array}$ & $\begin{array}{l}\text { Group } 2 \\
(\text { dGEMRIC } \geq 332 \mathrm{~ms})\end{array}$ & $\begin{array}{l}\text { Group } 1 \\
\text { versus Group } 2\end{array}$ & $\begin{array}{l}\text { Group } 1 \text { baseline } \\
\text { versus followup }\end{array}$ & $\begin{array}{l}\text { Group } 2 \text { baseline } \\
\text { versus followup }\end{array}$ \\
\hline dGEMRIC index (ms) & $302 \pm 39$ & $563 \pm 137$ & 0.001 & & \\
\hline Age (years) & $29 \pm 5$ & $31 \pm 8$ & 0.593 & & \\
\hline $\begin{array}{l}\text { Number of hips with Tönnis } \\
\text { osteoarthritis Grade }>0(\%)\end{array}$ & $2(40)$ & $7(47)$ & 0.765 & & \\
\hline Baseline WOMAC (0-240) & $15 \pm 12$ & $76 \pm 34$ & 0.022 & 0.273 & 0.003 \\
\hline Followup WOMAC (0-240) & $6 \pm 4$ & $27 \pm 29$ & 0.037 & & \\
\hline Change in WOMAC after 1 year & $-9 \pm 16$ & $-48 \pm 35$ & 0.013 & & \\
\hline Baseline HOOS (0-100) & $74 \pm 5$ & $57 \pm 17$ & 0.027 & 0.287 & 0.012 \\
\hline Followup HOOS (0-100) & $85 \pm 9$ & $76 \pm 19$ & 0.316 & & \\
\hline Change in HOOS after 1 year & $11 \pm 13$ & $19 \pm 17$ & 0.471 & & \\
\hline Baseline MHHS (0-91) & $68 \pm 18$ & $53 \pm 16$ & 0.198 & 0.152 & 0.005 \\
\hline Followup MHHS (0-91) & $81 \pm 9$ & $71 \pm 15$ & 0.172 & & \\
\hline Change in MHHS after 1 year & $12 \pm 13$ & $18 \pm 17$ & 0.515 & & \\
\hline
\end{tabular}

Values are mean $\pm \mathrm{SD}$; dGEMRIC $=$ delayed gadolinium-enhanced MRI of cartilage; WOMAC $=$ Western Ontario and McMaster Universities Osteoarthritis Index; HOOS = Hip disability and Osteoarthritis Outcome Score; mHHS = modified Harris hip score. 
Table 11. Comparison of dGEMRIC indices of intact and degenerated cartilage by quadrant

\begin{tabular}{|c|c|c|c|c|c|c|c|c|c|}
\hline \multirow{3}{*}{$\begin{array}{l}\text { Intraoperative cartilage } \\
\text { assessment } \\
\text { Quadrant }\end{array}$} & \multicolumn{6}{|c|}{ Acetabular dGEMRIC indices (ms) } & \multicolumn{3}{|l|}{$\mathrm{p}$ value } \\
\hline & \multicolumn{3}{|c|}{ Disease-positive } & \multicolumn{3}{|c|}{ Disease-negative } & \multirow{2}{*}{$\begin{array}{l}\text { Peripheral } \\
\text { versus } \\
\text { peripheral }\end{array}$} & \multirow{2}{*}{$\begin{array}{l}\text { Central } \\
\text { versus } \\
\text { central }\end{array}$} & \multirow{2}{*}{$\begin{array}{l}\text { Combined } \\
\text { versus } \\
\text { combined }\end{array}$} \\
\hline & Peripheral & Central & Combined & Peripheral & Central & Combined & & & \\
\hline $\begin{array}{l}\text { AS }\left(12^{\circ}-3^{\circ}\right) \\
\text { Beck }>2(12 / 18 \text { hips })\end{array}$ & $510 \pm 237$ & $481 \pm 198$ & $496 \pm 217$ & $515 \pm 174$ & $500 \pm 148$ & $508 \pm 160$ & 0.918 & 0.66 & 0.715 \\
\hline $\begin{array}{l}\text { PS }\left(12^{\circ}-9^{\circ}\right) \\
\text { Beck }>0(7 / 18 \text { hips })\end{array}$ & $473 \pm 224$ & $415 \pm 185$ & $444 \pm 205$ & $651 \pm 220$ & $534 \pm 166$ & $592 \pm 203$ & 0.002 & 0.008 & $<0.001$ \\
\hline
\end{tabular}

Values are mean $\pm \mathrm{SD}$; dGEMRIC $=$ delayed gadolinium-enhanced MRI of cartilage; $\mathrm{AS}=$ anterosuperior; PS = posterosuperior.

symptomatic subjects with FAI indicate that acetabular and femoral cartilage degeneration progresses at short term.

We observed a uniform decline of the mean peripheral and central acetabular and femoral dGEMRIC indices. This is in contrast to dGEMRIC studies in dysplastic hips in which a more focal decline of the dGEMRIC value was observed at early followup. By using radial reformats, Hingsammer et al. [17] observed the changes mainly in the superior cartilage areas, which are exposed to substantially higher static stress in dysplastic hips $[19,56]$. This stress is reduced by redirectional osteotomy. Based on the fact that mechanical loading affects the cartilage GAG content, it has been suggested that the persistent decline in dGMERIC indices reflects normalization of the static overload in dysplastic hips [17]. In contrast to dysplastic hips with static overload, hips with FAI suffer from dynamic stress resulting from the pathologic contact. Given the different pathomechanism, the extent of intraarticular surgery, we believe that the uniform dGEMRIC decrease could reflect "normal" postsurgical inflammation rather than osteoarthritis progression.

Although the predictive value of dGEMRIC for the clinical outcome in patients undergoing PAO for hip dysplasia has been established [10, 25], limited data are available in patients with FAI with differing results $[9,18]$. In contrast to our findings, neither Chandrasekaran et al. nor Hingsammer et al. could establish a correlation between the baseline dGEMRIC index and the change in PROM $[9,18]$. The main reason for this might be the measurement technique. We obtained 3-D dGEMRIC maps, which allowed reformation of radial slices to achieve circumferential mapping of the entire cartilage, thereby covering all potential areas of prearthritic cartilage damage. Hingsammer at al. [18] and Chandrasekaran et al. [9] used one sagittal or a few coronal images only. With this approach, regions typically involved in advanced cartilage degeneration can easily be missed or underdiagnosed. We found that the change in WOMAC score correlated not only with the dGEMRIC index of the entire joint cartilage, but also with the central or peripheral dGEMRIC index of the superior quadrants. The correlation in strength of the regression analysis was comparable (Table 9). This means that fast assessment at the antero- or posterosuperior quadrant only could be used reliably as a predictor in clinical practice.

As a result of the small sample size, we did not try to directly correlate between dGEMRIC and intraoperatively graded cartilage lesions. Nevertheless, when using a dichotomous analysis, the mean posterosuperior dGEMRIC indices differed between surgically confirmed intact and degenerated cartilage. This was not the case for the anterosuperior quadrant, most likely as a result of the high prevalence of chondral lesions (Fig. 8). In an earlier study a weak correlation between combined dGEMRIC indices and Beck grading for cartilage lesions in the setting of FAI was demonstrated [6]. More recently analysis of regional dGEMRIC measurements achieved a moderate to strong correlation between biochemical MRI and intraoperative Beck grading. These results highlight the importance of performing regional mapping of dGEMRIC indices in patients with FAI, which may be further facilitated by using automated postprocessed planar maps [8].

In conclusion, we observed a paradoxic decline in dGEMRIC index 1 year after joint-preserving hip surgery for FAI despite clinical improvement in this planned preliminary analysis. Analogously, we observed a similar decrease in the dGEMRIC index in symptomatic patients without surgical treatment but to a much lesser degree. Patient selection for FAI surgery may be improved by our observation that patients with more severe symptoms and high baseline dGEMRIC indices benefited more from jointpreserving surgery than those with lower dGEMRIC indices and less severe symptoms. Although treatment of FAI is intended to alter the shear forces acting across the hip by eliminating impingement, its effects on cartilage biology are not clear. dGEMRIC provides a noninvasive method of assessing these effects. The observed decline in dGEMRIC indices neither confirms the benefit of surgical treatment of FAI nor does it disprove the first reported favorable long- 


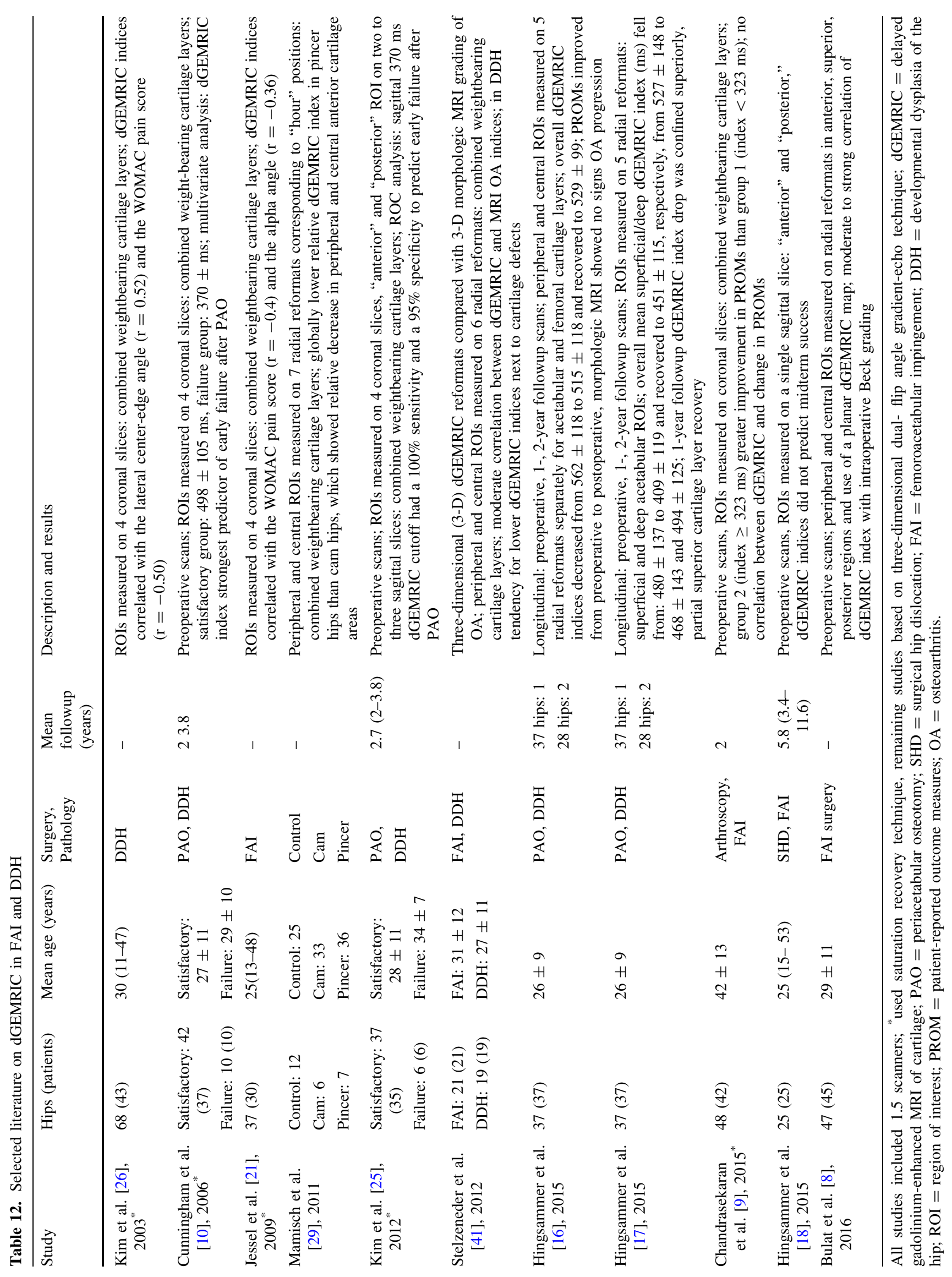




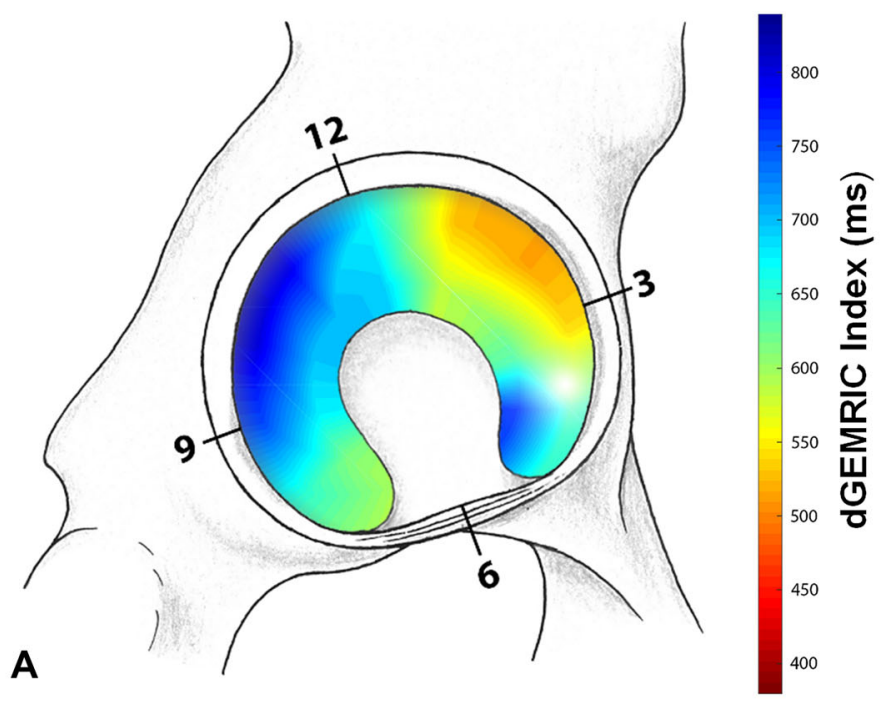

C
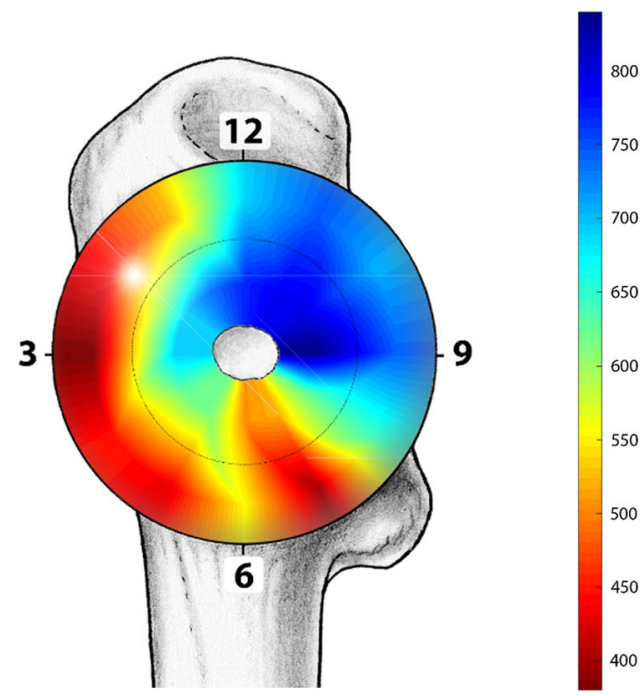

Fig. 8A-D An illustrative case of a 27-year-old woman undergoing surgical hip dislocation for mixed-type FAI is shown. (A) The preoperative dGEMRIC map indicates severe acetabular cartilage damage in the anterosuperior quadrant. (B) The corresponding intraarticular damage during surgical hip dislocation confirms the cartilage degeneration (arrows). (C) The preoperative dGEMRIC map

term results after FAI surgery in the literature [43]. Longer term studies will be needed to determine whether the cartilage matrix changes seen here are permanent or reversible.

Acknowledgments We thank Dr. Eduardo N. Novais for help in the preparation of the manuscript. Funding was provided by Schweizerischer Nationalfonds zur Förderung der Wissenschaftlichen Forschung.

\section{References}

1. Agricola R, Heijboer MP, Bierma-Zeinstra SMA, Verhaar JAN, Weinans H, Waarsing JH. Cam impingement causes osteoarthritis
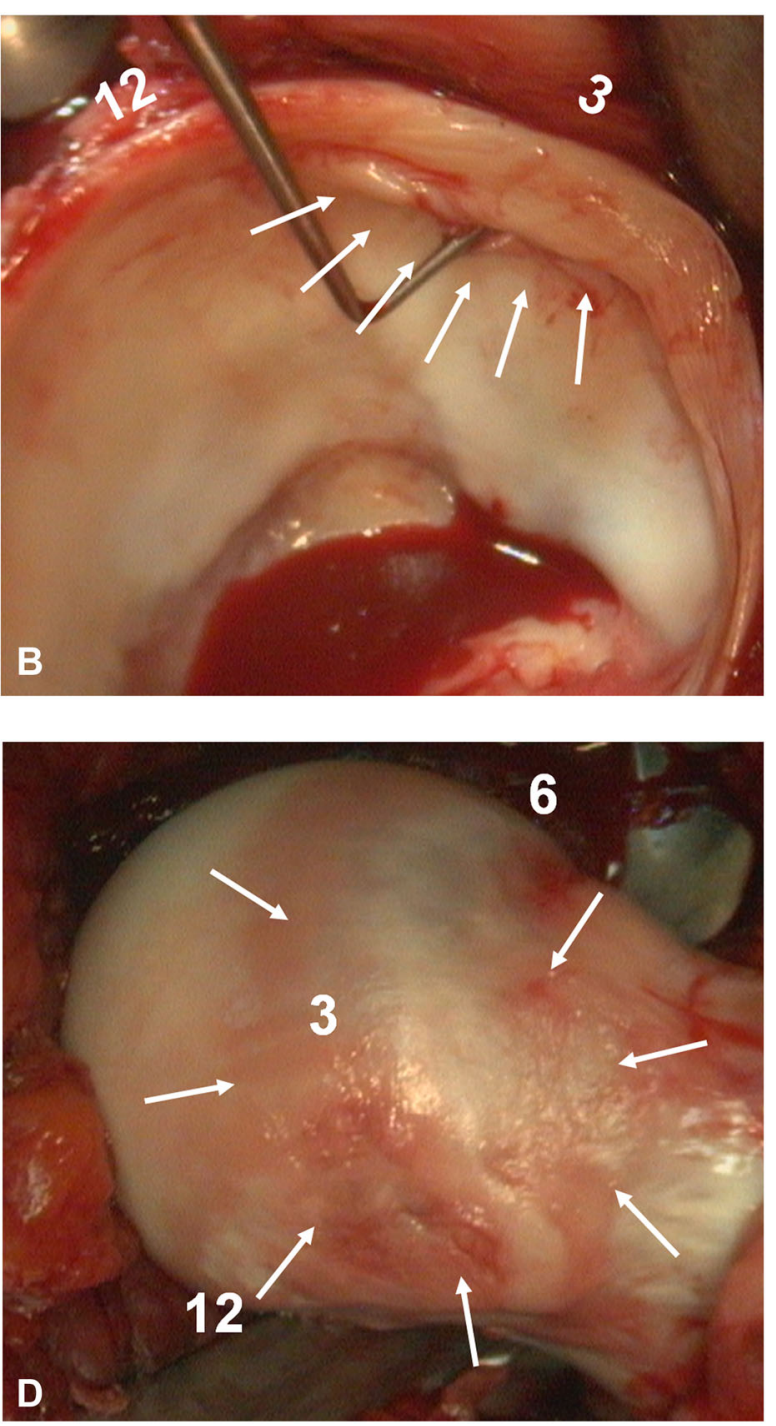

of the femoral cartilage indicates severe damage in the anterior peripheral aspect of the femoral head. (D) The corresponding intraarticular damage during surgical dislocation of the hip nicely reveals this peripheral femoral cartilage damage (arrows).

of the hip: a nationwide prospective cohort study (CHECK). Ann Rheum Dis. 2013;72:918-923.

2. Beaulé PE, Hynes K, Parker G, Kemp KA. Can the alpha angle assessment of cam impingement predict acetabular cartilage delamination? Clin Orthop Relat Res. 2012;470:3361-3367.

3. Beck M, Kalhor M, Leunig M, Ganz R. Hip morphology influences the pattern of damage to the acetabular cartilage: femoroacetabular impingement as a cause of early osteoarthritis of the hip. J Bone Joint Surg Br. 2005;87:1012-1018.

4. Bekkers JEJ, Bartels LW, Benink RJ, Tsuchida AI, Vincken KL, Dhert WJA, Creemers LB, Saris DBF. Delayed gadolinium enhanced MRI of cartilage (dGEMRIC) can be effectively applied for longitudinal cohort evaluation of articular cartilage regeneration. Osteoarthritis Cartilage. 2013;21:943-949.

5. Bellamy N, Buchanan WW, Goldsmith $\mathrm{CH}$, Campbell J, Stitt LW. Validation study of WOMAC: a health status instrument for measuring clinically important patient relevant outcomes to 
antirheumatic drug therapy in patients with osteoarthritis of the hip or knee. J Rheumatol. 1988;15:1833-1840.

6. Bittersohl B, Hosalkar HS, Apprich S, Werlen SA, Siebenrock KA, Mamisch TC. Comparison of pre-operative dGEMRIC imaging with intra-operative findings in femoroacetabular impingement: preliminary findings. Skeletal Radiol. 2011;40:553-561.

7. Blankenbaker DG, Ullrick SR, Kijowski R, Davis KW, De Smet AA, Shinki K, Muñoz del Rio A, Keene JS. MR arthrography of the hip: comparison of IDEAL-SPGR volume sequence to standard MR sequences in the detection and grading of cartilage lesions. Radiology. 2011;261:863-871.

8. Bulat E, Bixby SD, Siversson C, Kalish LA, Warfield SK, Kim Y-J. Planar dGEMRIC maps may aid imaging assessment of cartilage damage in femoroacetabular impingement. Clin Orthop Relat Res. 2016;474:467-478.

9. Chandrasekaran S, Vemula SP, Lindner D, Lodhia P, SuarezAhedo C, Domb BG. Preoperative delayed gadolinium-enhanced magnetic resonance imaging of cartilage (dGEMRIC) for patients undergoing hip arthroscopy: indices are predictive of magnitude of improvement in two-year patient-reported outcomes. $J$ Bone Joint Surg Am. 2015;97:1305-1315.

10. Cunningham T, Jessel R, Zurakowski D, Millis MB, Kim Y-J. Delayed gadolinium-enhanced magnetic resonance imaging of cartilage to predict early failure of Bernese periacetabular osteotomy for hip dysplasia. $J$ Bone Joint Surg Am. 2006;88:1540-1548.

11. Ganz R, Gill TJ, Gautier E, Ganz K, Krügel N, Berlemann U. Surgical dislocation of the adult hip a technique with full access to the femoral head and acetabulum without the risk of avascular necrosis. J Bone Joint Surg Br. 2001;83:1119-1124.

12. Ganz R, Parvizi J, Beck M, Leunig M, Nötzli H, Siebenrock KA. Femoroacetabular impingement: a cause for osteoarthritis of the hip. Clin Orthop Relat Res. 2003;417:112-120.

13. Glynn AA, Barattiero FY, Albers CE, Hanke MS, Steppacher SD, Tannast M. Surgical hip dislocation does not result in atrophy or fatty infiltration of periarticular hip muscles. J Hip Preserv Surg. 2014;1:82-95.

14. Harris WH. Traumatic arthritis of the hip after dislocation and acetabular fractures: treatment by mold arthroplasty. An end-result study using a new method of result evaluation. J Bone Joint Surg Am. 1969;51:737-755.

15. Hauselmann HJ, Flechtenmacher J, Michal L, Thonar EJ, Shinmei M, Kuettner KE, Aydelotte MB. The superficial layer of human articular cartilage is more susceptible to interleukin-1induced damage than the deeper layers. Arthritis Rheum. 1996;39:478-488.

16. Hingsammer AM, Kalish LA, Stelzeneder D, Bixby S, Mamisch TC, Connell P, Millis MB, Kim Y-J. Does periacetabular osteotomy for hip dysplasia modulate cartilage biochemistry? $J$ Bone Joint Surg Am. 2015;97:544-550.

17. Hingsammer AM, Miller PE, Millis MB, Kim Y-J. Does periacetabular osteotomy have depth-related effects on the articular cartilage of the hip? Clin Orthop Relat Res. 2015;473:3735-3743.

18. Hingsammer AM, Stelzeneder D, Kalish LA, Millis MB, Kim YJ. Prognostic factors for mid-term symptom relief after open surgical correction for femoroacetabular impingement. Hip Int. 2015;25:406-412.

19. Hipp JA, Sugano N, Millis MB, Murphy SB. Planning acetabular redirection osteotomies based on joint contact pressures. Clin Orthop Relat Res. 1999;364:134-143.

20. Holm I, Bolstad B, Lütken T, Ervik A, Røkkum M, Steen H. Reliability of goniometric measurements and visual estimates of hip ROM in patients with osteoarthrosis. Physiother Res Int. 2000;5:241-248.

21. Jessel RH, Zilkens C, Tiderius C, Dudda M, Mamisch TC, Kim Y-J. Assessment of osteoarthritis in hips with femoroacetabular impingement using delayed gadolinium enhanced MRI of cartilage. J Magn Reson Imaging. 2009;30:1110-1115.

22. Jessel RH, Zurakowski D, Zilkens C, Burstein D, Gray ML, Kim Y-J. Radiographic and patient factors associated with pre-radiographic osteoarthritis in hip dysplasia. J Bone Joint Surg Am. 2009;91:1120-1129.

23. Kalberer F, Sierra RJ, Madan SS, Ganz R, Leunig M. Ischial spine projection into the pelvis: a new sign for acetabular retroversion. Clin Orthop Relat Res. 2008;466:677-683.

24. Khan M, Ayeni OR, Madden K, Bedi A, Ranawat A, Kelly BT, Sancheti P, Ejnisman L, Tsiridis E, Bhandari M. Femoroacetabular Impingement: have we hit a global tipping point in diagnosis and treatment? Results from the InterNational Femoroacetabular Impingement Optimal Care Update Survey (IN FOCUS). Arthroscopy. 2016;32:779-787.e4.

25. Kim SD, Jessel R, Zurakowski D, Millis MB, Kim Y-J. Anterior delayed gadolinium-enhanced MRI of cartilage values predict joint failure after periacetabular osteotomy. Clin Orthop Relat Res. 2012;470:3332-3341.

26. Kim Y-J, Jaramillo D, Millis MB, Gray ML, Burstein D. Assessment of early osteoarthritis in hip dysplasia with delayed gadolinium-enhanced magnetic resonance imaging of cartilage. $J$ Bone Joint Surg Am. 2003;85:1987-1992.

27. Klässbo M, Larsson E, Mannevik E. Hip disability and osteoarthritis outcome score. An extension of the Western Ontario and McMaster Universities Osteoarthritis Index. Scand $J$ Rheumatol. 2003;32:46-51.

28. Klenke FM, Hoffmann DB, Cross BJ, Siebenrock KA. Validation of a standardized mapping system of the hip joint for radial MRA sequencing. Skeletal Radiol. 2015;44:339-343.

29. Mamisch TC, Kain MSH, Bittersohl B, Apprich S, Werlen S, Beck M, Siebenrock KA. Delayed gadolinium-enhanced magnetic resonance imaging of cartilage (dGEMRIC) in femoacetabular impingement. J Orthop Res. 2011;29:1305-1311.

30. Martin RL, Sekiya JK. The interrater reliability of 4 clinical tests used to assess individuals with musculoskeletal hip pain. $J$ Orthop Sports Phys Ther. 2008;38:71-77.

31. McWhirk LB, Glanzman AM. Within-session inter-rater realiability of goniometric measures in patients with spastic cerebral palsy. Pediatr Phys Ther. 2006;18:262-265.

32. Murphy SB, Simon SR, Kijewski PK, Wilkinson RH, Griscom NT. Femoral anteversion. J Bone Joint Surg Am. 1987;69:11691176.

33. Naal FD, Miozzari HH, Schär M, Hesper T, Nötzli HP. Midterm results of surgical hip dislocation for the treatment of femoroacetabular impingement. Am $J$ Sports Med. 2012;40:1501-1510.

34. Neuman P, Owman H, Müller G, Englund M, Tiderius CJ, Dahlberg LE. Knee cartilage assessment with MRI (dGEMRIC) and subjective knee function in ACL injured copers: a cohort study with a 20 year follow-up. Osteoarthritis Cartilage. 2014;22:84-90.

35. Ng VY, Arora N, Best TM, Pan X, Ellis TJ. Efficacy of surgery for femoroacetabular impingement: a systematic review. Am J Sports Med. 2010;38:2337-2345.

36. Pfirrmann CWA, Duc SR, Zanetti M, Dora C, Hodler J. MR arthrography of acetabular cartilage delamination in femoroacetabular cam impingement. Radiology. 2008;249:236-241.

37. Rogers BA, Murphy CL, Cannon SR, Briggs TWR. Topographical variation in glycosaminoglycan content in human articular cartilage. J Bone Joint Surg Br. 2006;88:1670-1674.

38. Rosset A, Spadola L, Ratib O. OsiriX: an open-source software for navigating in multidimensional DICOM images. $J$ Digit Imaging. 2004; 17:205-216.

39. Siebenrock $\mathrm{K}$, Attinger $\mathrm{M}$, Steppacher $\mathrm{S}$, Tannast $\mathrm{M}$. Femoroacetabular impingement—current understanding. In: 
Johari, A, Luk KDK, Waddell J, eds. Current Progress in Orthopedics 1. Mumbai, India: Kothari Medical Subscription Services; 2014:1-26.

40. Siversson C, Chan J, Tiderius C-J, Mamisch TC, Jellus V, Svensson J, Kim Y-J. Effects of B1 inhomogeneity correction for three-dimensional variable flip angle T1 measurements in hip dGEMRIC at $3 \mathrm{~T}$ and 1.5 T. Magn Reson Med. 2012;67:1776-1781.

41. Stelzeneder D, Mamisch TC, Kress I, Domayer SE, Werlen S, Bixby SD, Millis MB, Kim Y-J. Patterns of joint damage seen on MRI in early hip osteoarthritis due to structural hip deformities. Osteoarthritis Cartilage. 2012;20:661-669.

42. Steppacher S, Schwab J, Siebenrock K, Tannast M. Actual management of femoroacetabular impingement. Minerva ortopedica e traumatologica. 2012;63:365-378.

43. Steppacher SD, Anwander H, Zurmühle CA, Tannast M, Siebenrock KA. Eighty percent of patients with surgical hip dislocation for femoroacetabular impingement have a good clinical result without osteoarthritis progression at 10 years. Clin Orthop Relat Res. 2015;473:1333-1341.

44. Steppacher SD, Lerch TD, Gharanizadeh K, Liechti EF, Werlen SF, Puls M, Tannast M, Siebenrock KA. Size and shape of the lunate surface in different types of pincer impingement: theoretical implications for surgical therapy. Osteoarthritis Cartilage. 2014;22:951-958.

45. Sutter R, Dietrich TJ, Zingg PO, Pfirrmann CWA. How useful is the alpha angle for discriminating between symptomatic patients with cam-type femoroacetabular impingement and asymptomatic volunteers? Radiology. 2012;264:514-521.

46. Sutter R, Zubler V, Hoffmann A, Mamisch-Saupe N, Dora C, Kalberer F, Zanetti M, Hodler J, Pfirrmann CWA. Hip MRI: how useful is intraarticular contrast material for evaluating surgically proven lesions of the labrum and articular cartilage? AJR Am J Roentgenol. 2014;202:160-169.

47. Tannast M, Fritsch S, Zheng G, Siebenrock KA, Steppacher SD. Which radiographic hip parameters do not have to be corrected for pelvic rotation and tilt? Clin Orthop Relat Res. 2015;473:1255-1266.

48. Tannast M, Goricki D, Beck M, Murphy SB, Siebenrock KA. Hip damage occurs at the zone of femoroacetabular impingement. Clin Orthop Relat Res. 2008;466:273-280.
49. Tannast M, Leunig M, Session Participants. Report of breakout session: Coxa profunda/protrusio management. Clin Orthop Relat Res. 2012;470:3459-3461.

50. Tannast M, Mistry S, Steppacher SD, Reichenbach S, Langlotz F, Siebenrock KA, Zheng G. Radiographic analysis of femoroacetabular impingement with Hip2Norm-reliable and validated. $J$ Orthop Res. 2008;26:1199-1205.

51. Tannast M, Siebenrock KA, Anderson SE. Femoroacetabular impingement: radiographic diagnosis-what the radiologist should know. AJR Am J Roentgenol. 2007;188:1540-1552.

52. Tiderius C, Hori M, Williams A, Sharma L, Prasad PV, Finnell M, McKenzie C, Burstein D. dGEMRIC as a function of BMI. Osteoarthritis Cartilage. 2006;14:1091-1097.

53. Tiderius CJ, Jessel R, Kim Y-J, Burstein D. Hip dGEMRIC in asymptomatic volunteers and patients with early osteoarthritis: the influence of timing after contrast injection. Magn Reson Med. 2007;57:803-805.

54. Tönnis D. General radiography of the hip joint. In: Tönnis D, ed. Congenital Dysplasia, Dislocation of the Hip. New York, NY, USA: Springer; 1987.

55. Wyss TF, Clark JM, Weishaupt D, Nötzli HP. Correlation between internal rotation and bony anatomy in the hip. Clin Orthop Relat Res. 2007;460:152-158.

56. Zhao X, Chosa E, Totoribe K, Deng G. Effect of periacetabular osteotomy for acetabular dysplasia clarified by three-dimensional finite element analysis. J Orthop Sci. 2010;15:632-640.

57. Zheng G, Tannast M, Anderegg C, Siebenrock KA, Langlotz F. Hip2Norm: an object-oriented cross-platform program for 3D analysis of hip joint morphology using 2D pelvic radiographs. Comput Methods Programs Biomed. 2007;87:36-45.

58. Zilkens C, Miese F, Kim Y-J, Jäger M, Mamisch TC, Hosalkar H, Antoch G, Krauspe R, Bittersohl B. Direct comparison of intra-articular versus intravenous delayed gadolinium-enhanced MRI of hip joint cartilage. J Magn Reson Imaging. 2014;39:94102.

59. Zilkens C, Tiderius CJ, Krauspe R, Bittersohl B. Current knowledge and importance of dGEMRIC techniques in diagnosis of hip joint diseases. Skeletal Radiol. 2015;44:1073-1083. 